School of Finance

University of St.Gallen

IMMIGRATION AND THE DISPLACEMENT OF INCUMBENT HOUSEHOLDS

ZeNO ADAMS

KRISITAN BLICKLE

WORKING PAPERS ON FinANCE No. 2018/8

SWISS INSTITUTE OF BANKING AND FINANCE (S/BF - HSG)

February 2018 


\title{
Immigration and the Displacement of Incumbent Households*
}

\author{
Zeno Adams ${ }^{\ddagger}$ and Kristian Blickle ${ }^{\S}$
}

First distributed: May 2016

This version: February 2018

* We thank Martin Brown, Geraldo Cerqueiro, Beatrix Eugster, Andreas Fischer, Andreas Fuster, Hans Gersbach, Xavier Giroud, Luigi Guiso, Winfried Koeniger, Sören Leth-Pedersen, Christoph Merkle, Stijn Van Nieuwerburgh, Rafael Parchet, Daniel Ruf, Norman Schürhoff, Thomas Spycher, Anthony Strittmatter, James Vickery, Josef Zweimüller, and participants of the University of St. Gallen Research Seminar, the ERES 2016 annual meeting, the Research in Behavioral Finance Conference (RBFC 2016), the 14th International Paris Finance Meeting 2016, and the SSES 2017 annual meeting for valuable comments and suggestions. All errors are our own.

$\$$ Zeno Adams, Swiss Institute of Banking and Finance, University of St.Gallen, Unterer Graben 21, 9000 St. Gallen, Switzerland, Phone: +41 (0)71 224 7057, Fax: +41 (0)71 224 7088, Email: zeno.adams@unisg.ch.

$\S$ Kristian Blickle, Swiss Institute of Banking and Finance, University of St.Gallen, Unterer Graben 21, 9000 St. Gallen, Switzerland, Phone: +41 (0)71 224 7040, Fax: +41 (0)71 2247088 , Email: kristian.blickle@unisg.ch. 


\title{
Immigration and the Displacement of Incumbent Households
}

\begin{abstract}
We make use of the universe of immigrants who arrived in Switzerland between 1992 and 2013, granular community level house price and wage data as well as detailed information on the Swiss population to study the effects of immigration on the location choice of incumbent households. Immigration influences a household's location choice through three distinct channels: house price changes, labor market competition, and households' sentiment regarding immigration. We find evidence of all three channels. However, we show that the channel to which a household responds most strongly depends on the type of immigration and the characteristics of the household. Our research provides valuable insights into some of the effects of large scale immigration.
\end{abstract}

Keywords: Immigration, house prices, wages, employment, gentrification, displacement

JEL-Classification: $\quad D 14, D 9, J 61, R 21, R 23$ 


\section{Introduction}

Human rights groups report an increase in the number of people that have been displaced by social conflict or poverty over the past few years. Particularly in Europe and the United States, which have seen a surge in the number of displaced people arriving each year, this has led to a renewed debate about the effects of immigration on the incumbent population. These debates have focused in part on whether immigrants may displace incumbent households (i.e. force them to relocate). However, despite the importance of the topic, little conclusive empirical evidence exists on the subject. On the one hand, this is due to the fact that immigration may exert heterogeneous pressure on households based on the characteristics of the immigrants and the households in question ${ }^{1}$. Aggregate analyses may consequently have difficulty in identifying clear effects. On the other hand, this may be due to the fact that sufficiently detailed data is hard to come by. This paper contributes substantially by making use of uniquely detailed data to analyze the potential for immigrants to displace incumbent households.

We use our data to analyze three distinct channels through which immigrants may affect the location choice of incumbents, while controlling for a host of location and household-specific characteristics. Firstly, households may relocate due to changes in house prices and rents. After all, certain neighborhoods may experience price-hikes that follow immigration-induced demand for housing. Secondly, immigration may affect wages (positively or negatively) through labor market complementarity or competition effects. Households that experience wage changes might in turn be induced to move to a different municipality. Finally, households, which exhibit a strong preference regarding the composition of their neighborhood, might see immigration as an incentive to relocate. We label this a "sentiment" channel and define it as the displacement pressure exerted by immigration, when all neighborhood and household-level characteristics, which may induce relocation, are controlled for. It should be noted that this channel may in part capture a household's expectation of future labor- or housing-market competition, as opposed to a preference for neighborhoods of homogenous ethnicity. However, viewing all three channels together yields a holistic picture of immigration and displacement.

We further complement this holistic picture by looking at both aggregate municipality-level effects and individual household-level effects. Estimates from municipality level data benefit from

\footnotetext{
${ }^{1}$ For instance, while some households benefit from services provided by low-skilled immigrants, others face labor market competition and falling wages (Cortes, 2008; Ottaviano and Peri, 2011; Beerli and Peri, 2017).
} 
a large number of observations and show the overall response for a region. However, aggregate results alone cannot capture the heterogeneity across individual households. While some households are adversely affected by immigration, others may benefit from higher house prices (i.e. owners) or additional demand and labor supply. We therefore discuss a second, complementary set of regressions that can be related to specific household characteristics such as whether a household is a tenant or owner, has pressure to relocate or has high levels of income. A joint analysis of the empirical evidence from both aggregation levels sheds light on the relationship between individual behavior and collective outcomes and helps resolve a number of conflicting findings in the literature.

We focus on Switzerland, an optimal laboratory for analyzing the effects of immigration. Firstly, Switzerland has among the highest rates of per-capita immigration of any OECD country. ${ }^{2}$ Concerns about the impacts from large-scale immigration is therefore a dominant topic in Swiss politics and society. Secondly, Switzerland underwent different phases of immigration which were characterized by a strong heterogeneity with respect to education, wealth and cultural background of immigrants. For instance, immigration flows at the beginning of our sample in the mid-90s, are dominated by refugees from the wars that followed the collapse of Yugoslavia. In contrast, immigrant flows in more recent years are mainly from Germany with immigrants pursuing higher paid jobs in the health or education sector. These two groups of immigrants differ with respect to the incomes they earn on the labor market and hence their potential to affect house prices and socioeconomic change. Finally, Switzerland is culturally and linguistically similar to its neighbors (France, Germany, and Italy) who are themselves currently dealing with high rates of immigration. The implications of our results are therefore relevant for other countries.

We make use of the universe of immigrants who arrived between 1992 and 2013, municipality-level transaction-based house prices, and municipality-level information on the number of Swiss households and the average wages of households in these municipalities. Using this comprehensive Swiss-wide data, we can show the displacement-effects of exogenous (or

\footnotetext{
${ }^{2}$ According to the OECD, the share of foreigners in Switzerland is currently 24\%, the second highest in Europe behind the much smaller Luxembourg.
} 
"pushed") immigration across the entire country. ${ }^{3}$ We supplement country-wide information with detailed data on location, characteristics, wages and sentiments of over 7,000 households recorded for 15 years. Using this survey data, we are able to control for confounding household characteristics or changes in its composition (such as new birth or divorce) that might induce relocation. Consequently, we are able to isolate those households most affected by immigration.

Our empirical results can be summarized as follows: First, we find that exogenous immigration causes an increase in house prices. The exact nature of the increase depends on the origin of the immigrants in question. An increase of the population by one percentage point due to immigration from Western Europe or OECD countries cause a $1.15 \%$ increase in house prices on average. ${ }^{4}$ Immigration from the rest of the world (RoW) have a somewhat lower $0.37 \%$ impact. This is possibly related to the more limited purchasing power of some immigrants. In line with these price reactions, we find evidence for price-induced relocation. A one standard deviation increase in house prices will increase the propensity at which households relocate by 0.33 percentage points, but only if the household has a pre-existing desire to move. If a household has no desire to relocate, house prices even reduce the relocation probability. This finding can be explained in part by the peculiarities of the Swiss rental law, which "locks in" the price of existing rental contracts thereby making rising prices a deterrent to relocation. Second, we find evidence of a wage effect. A one percentage point increase in the local population due to immigration from Western Europe or OECD countries will reduce labor income of wealthy households by $1.7 \%$ and increase the income of less wealthy households by about $1.5 \%$. In contrast, a $1 \%$ increase in immigration from rest of world countries will reduce the income of less wealthy households by $0.95 \%$ and leave the income of wealthier households unchanged. Higher wages are positively correlated with moving to a new municipality. This can be explained by households' desire to upgrade to a better housing standard once higher incomes are earned. It also implies that preexisting rental contracts (with locked in rental rates) become more attractive in the face of falling wages. Finally, controlling for price changes and wages, we find that an increase of the population

\footnotetext{
${ }^{3}$ In order to ensure our measure of immigration is exogenous to local conditions, we make use of exogenous or "pushed" immigration (i.e. a Bartik-style instrument), as developed for the immigration literature by Card (2001) and more recently applied by Halle et al. (2014) and Basten and Koch (2015).

${ }^{4}$ We exclude Portugal from this list because the characteristics of the Portuguese immigrants in our data are more similar to other rest of world immigrants.
} 
by one percentage point due to immigration from Western Europe and OECD countries increase the propensity that both home owners and tenants relocate by 0.5 to 1 percentage points. This effect is larger than the effect directly related to house price changes or wage changes. It is important to note, however, that these results vary greatly between different types of households; the corresponding sensitivities are discussed in detail below.

Overall, our estimates are slightly larger than the displacement effects of immigration reported in other studies for the US and the UK (e.g. Borjas, 2006; Logan and Zhang, 2010; Hatton and Tani, 2005). Particularities of the Swiss market, our detailed approach, as well as the magnitude of immigration, relative to the native population may explain our results (these are all discussed in detail below). Given the nature of our study, we contribute to the literature on immigration based house price changes, labor market competition, as well as the idea of sentiment induced displacement.

There are several empirical studies that focus on house price dynamics as a driving factor of household location choice. Guerrieri et al. (2013) show for the U.S. housing market that a positive demand shock on the city level leads to substantial variation in house price growth across city neighborhoods. The authors find that households respond to the spatial price heterogeneity by relocating to cheaper neighborhoods which in turn has feedback effects on prices. In our paper, we use a spatial regression model that can capture this type of household behavior by transmitting house price shocks to cheaper neighboring regions. Helms (2003) shows the strong relationship between renovation investment, associated house price improvements and gentrification of wealthy neighborhoods for inner Chicago ${ }^{5}$. Sieg et al. (2004) show that, following clean air regulation, parts of Los Angeles that experienced an improvement in air quality saw more substantial gentrification in association with house price growth. Sá (2014) examines the impact of immigration in the UK and finds no significant (instead even a negative) house price reaction. She conjectures that this is due to fact that some households may leave areas of high immigration, thereby dampening prices. However, she cannot show this empirically. Degen and Fischer (2017) and Basten and Koch (2015) specifically analyze the link between Swiss house prices and immigration. Similar to our study, they find that immigration is a significant driver of house prices, though they make use of much

${ }^{5}$ Several studies deal not only with gentrification-based price pressure but also with its long-term neighborhood effects. These include McKinnish et al. (2010) and O’Sullivan (2005) 
less granular data. Moreover, they do not link these dynamics directly to price-based relocation decisions of incumbent households. ${ }^{6}$

Several studies have analyzed the effects of labor market competition as induced by immigration $^{7}$. Card $(2001,2007,2009)$ finds little to no evidence of labor market displacement of incumbents by immigrants. Hatton and Tani (2005), looking at the UK, find that wages do not respond to immigration. They identify a strong relocation response from immigration as the main reason for this finding. As a consequence, the wage impact is spread out over several regions which explains why many studies find only small wage effects from immigration. In this paper, we use a panel spatial autoregressive model that accounts for the dissemination of wages to nearby municipalities. Kritz and Gurak (2001), in a US study, find little evidence that immigrants displace natives when accounting for local conditions. Borjas (2006), Filer (1992) and Frey (1995) find evidence of a large displacement effect, particularly for low-skilled native workers who migrate in response to the arrival of low-skilled foreign workers ${ }^{8}$. The size and direction of our own findings are in line with this strand of the literature. However, we also find a high degree of heterogeneity, depending on the type of immigration and the type of household in question. Our work thereby contributes to the above studies by using a rich dataset that allows us to make use of the universe of all immigrants on the one hand and controls of household-specific characteristics on the other.

Finally, we contribute to an as yet underdeveloped field of analysis in the context of displacement: sentiment. Sentiment can be difficult to disentangle from the above-mentioned labor market effects (or even house price effects). What we call "sentiment" will likely include a household's perception about increased labor market competition due to immigration, even if such competition has not yet had an immediate wage effect. Ha and Jang (2014) find evidence that increasing diversity brings a heightened ethnocentric response. Fitzgerald et al. (2012) and Wang (2012) show that immigration can be associated with a perceived threat: crime might increase and the host culture might be subverted. Similarly, Wright (2011), Esses et al., (2006) and Maddens et al. (2000) all show a correlation between feelings of national identity and public opinion regarding

${ }^{6}$ Other studies focusing directly on the link between immigration and house price dynamics include Ley et al. (2002) and Akbari and Aydede (2012) for Canada, Saiz (2007) for the US, and Gonzalez and Ortega (2013) for Spain.

${ }^{7}$ Lester and Hartley (2014) specifically consider the labor market implications of gentrification to show that employment grows slightly faster in gentrifying neighborhoods.

${ }^{8}$ Differences in their findings and those of David Card can be traced back to alternate model specifications as well as their use of different data (e.g. city vs. census-level), as was highlighted by Peri and Sparber (2011). 
immigration. It seems plausible that households, with strong feelings regarding national identity, may leave areas affected by high rates of immigration. We extend these studies by documenting evidence of such a possible phenomenon for Switzerland, while also accounting for other channels through which dissatisfaction or the impulse to relocate might be affected.

The remainder of this paper is structured as follows. Section 2 outlines the empirical design used in this paper. Section 3 describes our data and presents some preliminary summary statistics and comparisons. Section 4 details our results. We make an effort to show the sensitivity of our results to various definitions of immigration or different household characteristics. Section 5 concludes our findings.

\section{Economic Mechanism of Immigration and Displacement}

\subsection{Overview}

Immigration affects the housing market, the labor market, and the well-being of the native population in a number of ways. In this section, we aim to clarify the economic channels through which immigration operates. First, immigration can affect house prices and wages. Second, changes in house prices and wages, which have been caused by immigration, can influence the propensity of native households to relocate to different regions. Third, immigration may not only affect households' relocation decisions through the housing market and wage channel but could have a direct impact, which we interpret as a residual or sentiment channel. The three channels are summarized in Figure 1.

\section{$<<$ Figure 1 about here $>>$}

We gather empirical evidence for the transmission channels from two levels of aggregation. First, estimates from municipality level data benefit from a large number of observations and show the overall response for a region. These results are based on small geographic areas but are sufficiently aggregated to give representative effects. On the other hand, individual households are exposed to immigration in many different ways. While some households experience pressure from substitution effects, others benefit from additional demand and labor supply. An aggregate analysis cannot capture the variation across individual households. We therefore also estimate a second, complementary set of regressions that can be related to specific household characteristics such as whether a household is a tenant or owner, has pressure to relocate or has high levels of income. Since individual households are too small to cause feedback effects, household-level data also helps 
to address potential endogeneity within our regression models. A joint analysis of the empirical evidence from both aggregation levels sheds light on the relationship between individual behavior and collective outcomes and helps resolve a number of conflicting findings in the literature.

\subsection{Immigration affects House Prices and Wages}

Perhaps the most prominent effects of large-scale immigration, which also attracts considerable media attention, are the impacts on house prices and wages. In Figure 1, the house price and wage channel is denoted by Model I. Population is the main demand driver for residential real estate and an increasing population is expected to have a positive effect on house prices. The effects of Immigration on wages can be either positive, when immigrant's skills are complementary to the local economy (Rath and Kloosterman, 2000; Zelekha, 2013, Beerli and Peri, 2017) or negative, when immigrants compete with incumbent households on the labor market (Card, 2001; Orrenius and Zavodny, 2007; Ottaviano and Peri, 2011). We explore the heterogeneity of immigration types and show that the effects are multifaceted. We find that the size and the direction of the effects are correlated with the country of origin of the immigrants and that the response of wages depends on the type of households. For instance, low-income tenants tend to compete with less-educated immigrants on the labor market whereas high-income home owners are more affected by high skilled immigrants.

When measuring the impact of immigration, it is not clear a priori whether house prices rise because of additional demand from immigration or whether immigrants choose to locate to booming regions that also experience rising house prices and wages. The raw immigration variable is therefore likely to contain some amount of endogeneity that needs to be addressed. We follow the labor market literature which has tackled this issue over the last years with the method of Card (2001) having become a popular approach. Card decomposed overall immigration in each region into "push" and "pull" immigration. The push factor refers to variables that push immigrants out of their home country such as social and political instability or a lack of job opportunities. The push factors are exogenous to conditions in the country in which the immigrants chose to relocate. The pull factor represents variables the attract immigration such as job opportunities and a high standard of living. Pull factors are therefore likely to be endogenous. The aim of the Card (2001) decomposition is to focus on the exogenous push immigration only. To conserve space, we refer to the detailed description of this approach in the data section. 
The impact of immigration on house prices $H P_{t}^{r}$ is estimated in a panel regression for region $r$ over the years 1993-2014. Our regression specification accounts for the fact that house price effects from immigration are not confined to the shock originating region but are transmitted to neighboring regions (Guerrieri et al., 2013). We discuss the details of the specification in the empirical part below. To facilitate the discussion and improve readability, we concentrate here on a simplified expression:

$$
H P_{t}^{r}=\alpha_{1} O E C D_{t}^{r}+\alpha_{2} \text { RoW }_{t}^{r}+\alpha_{3}^{\prime} \text { controls }_{t}+\varepsilon_{t}^{r}
$$

Our main coefficients of interest in this model are $\alpha_{1}$ and $\alpha_{2}$ which measure the effect of an increase in exogenous pushed immigration from OECD countries and from the rest of the world. ${ }^{9}$ We use these two aggregate groups for simplicity throughout the paper. The vector of control variables includes municipality and time fixed effects as well as municipality specific vacancy rates. ${ }^{10}$ Eq.(1) serves as a benchmark model in which the regressors enter in contemporaneous form. Generally, the impacts from immigration on house prices, wages, and displacement can materialize over a course of several years. Below, we therefore also propose specifications that measure the impact of immigration over the last three years.

The impact of immigration on wages $W_{t}^{*}$ is estimated like the previous regression using wages for region $r$ over the years 2002-2013:

$$
W_{t}^{r}=\alpha_{1} \mathrm{OECD}_{t}^{r}+\alpha_{2} \text { RoW }_{t}^{r}+\alpha_{3}^{\prime} \text { controls }_{t}+\varepsilon_{t}^{r}
$$

Like before, we are interested in the coefficients $\alpha_{1}$ and $\alpha_{2}$ which measure the percentage response in wages to an increase in immigration from OECD and rest of world countries.

The specification in Eq.(2) is based on aggregate region level data and does not provide any information about the responses of individual households. One of the main findings in this paper

${ }^{9}$ In Appendix B, we also show regression results for individual countries. The OECD country group is dominated by immigrants from neighboring Germany. Given the fact that immigrants from Portugal and Eastern Europe have traditionally taken low-paying jobs in Switzerland, they are grouped into the "Rest of World" category for the purpose of our analyses, even if these countries would be OECD members.

${ }^{10}$ For instance, our municipality fixed effects control for the inflows of cross-border workers to municipalities which are within commuting distance to neighboring countries France, Germany, Austria, Liechtenstein, and Italy. Time fixed effects control for the gradual liberalization of the Swiss labor market for EU resident immigrants between 1999 and 2007 (Beerli and Peri, 2017) 
is that the impact on individual households and the household choices that emerge as a consequence often differ considerably from the aggregate effects. We can learn more about the wage impact on different types of households such as tenants, property owners, wealthy or poor households by regressing on the wages of individual households:

$$
W_{i t}^{\text {tenant/owner }}=\beta_{1} O E C D_{3 y r}^{r}+\beta_{2} R_{0} W_{3 y r}^{r}+\beta_{3}^{\prime} \text { controls }+\varepsilon_{i t}
$$

Equation (2') is estimated over the years 1999 to 2014, for which we have wages, immigration, and survey data for individual households. We estimate the impact of immigration over a three year period from $t-3$ to $t-1$ to account for a delayed wage response of households that are employed in strong labor union sectors with medium term wage settings.

We estimate the regression separately for tenants and owners accounting for a number of important household level characteristics such as age, education, marital status, and number of children. The tenant/owner separation is one that is maintained throughout the paper. Given our ultimate focus on the propensity of households to relocate, it is important to account for the different preferences of owners and tenants. In the empirical part of this paper, we will also show a version of Eq.(2') based on quantile regressions. Explicitly estimating the wage effects from immigration for different quantiles of the income distribution reveals a high degree of heterogeneity that is masked by the aggregate wage effect of the municipality level regressions but also by the average OLS estimates of the individual household effects.

\subsection{Immigration and displacement}

Immigration has a direct impact on real estate and labor markets. In this section, we are interested in the response of the incumbent Swiss population to these changes. In Figure 1, the causal chain is described as Model II where changes in house prices and wages form the transmission channels through which immigration affects incumbent households.

We begin by empirically quantifying the house price and the wage channel of displacement for individual incumbent households. We run two separate regressions for a household's propensity to move, Move $e_{\text {tenant }}$ ommer . The first regression tests for the hypothesis that households relocate following a house price increase while the second regression estimates a household's response to a decrease in wages.

The heterogeneity between households is higher than the heterogeneity between regions and the household level regressions reflect that fact. For instance, homeowners are more sensitive to 
house prices while tenants respond to rents. In addition, tenants with existing rent contracts benefit from the peculiarities of the Swiss tenancy law. In Switzerland, landlords have little discretion to adjust existing contracts. Instead, rent contracts can only appreciate by a small amount each quarter. The exact price increase is determined by a rent index that is the same for all regions and is calculated as the average mortgage rate across the Swiss cantons. ${ }^{11}$ As a consequence, prices paid by residents with old rent contracts are often far below market rates. These households would only be affected by higher local market rents if they would move to a new apartment. An increase in rents will therefore make relocating more unattractive for these types of households. This argument is confirmed by our data where we find that households which do not intend to move are less likely to relocate following an increase in rents. In contrast, households that have relocation pressure for instance because of marriage, divorce, or the birth of a child have a higher propensity to move following a rent or house price increase. Such households may be induced to relocate to cheaper communities, where they can afford to rent or purchase a suitable accommodation. The issue is summarized in Table 1. For tenants, we expect a positive coefficient on rent increases if the household intends to move but a negative coefficient if it does not. For owners, we also expect a positive price coefficient if the owner indicates that he intends to move but a negative price coefficient if the owners is not planning to move. We introduce a dummy $D_{i t}$ which is set to 1 if a household intends to move and is zero otherwise. ${ }^{12}$ We regress propensity to move, Move ${ }_{i t}^{\text {tenant/owner }}$, on house prices $H P_{t}^{r}$, the dummy $D_{i t}$, and the interaction between house prices and $D_{i t}$.

$$
\text { Move }_{i t+1}^{\text {tenant/owner }}=\beta_{1} H P_{t}^{r}+\beta_{2} D_{i t}+\beta_{3} H P_{t}^{r} \cdot D_{i t}+\beta_{4}^{\prime} \cdot \text { controls }+\varepsilon_{i t}^{r}
$$

The relocation variable $M o v e_{i t+1}^{\text {tenant/owner }}$ enters the regression with a lead of one year. Although we obtain very similar results with a contemporaneous specification, this setup ensures that house

11 This rent index is called "Hypothekarischer Referenzzinssatz" and is available at https://www.bwo.admin.ch/bwo/de/home/mietrecht/referenzzinssatz/entwicklung-referenzzinssatz-und-

durchschnittszinssatz.html.

12 "Intent to Move" is obtained from a survey question asked to households who participate in the Swiss household panel. Households can indicate their intention to move over the next 12 months on a range from 0 (no intention to move) to 10 (will certainly move). To facilitate interpretation in later regressions we generate a dummy that is 1 if intent to move is 8 or higher. Although this choice is to some extent arbitrary, it reflects a trade-off between restricting the variable to a relatively small number of households with high intention to move (intention $=10$ is only $4 \%$ of the sample) and households with values around 5 which are still relatively undecided. 
prices and other regressors have changed before households decide to move. Equation (3) is estimated separately for owners and tenants. In the case of tenants, $H P_{t}^{r}$ is replaced by rents. The estimate of $\beta_{3}$ can be used as a test of our hypothesis described in Table 1. In the empirical part of this paper, we verify that $D_{i t}$ is a key variable in understanding heterogeneous household responses to rising prices and rents.

Similar to the specification in Eq.(3), we are further interested in the effects of immigrationinduced wage changes on Move $e_{i t+1}^{\text {tenant/owner }}$. In Eq.(4) below we replace region specific house prices $H P_{t}^{r}$ by household specific wages $W_{i t}$. For consistency, and to facilitate the comparison with previous specifications, we maintain the tenant/owner specification throughout the paper.

$$
\operatorname{Move}_{\text {it+1 }}^{\text {tenantowner }}=\beta_{1} W_{i t}+\beta_{2} D_{i t}+\beta_{3} W_{i t} \cdot D_{i t}+\beta_{4}^{\prime} \cdot \text { controls }+\varepsilon_{i t}^{r}
$$

The time lead of one year in the dependent variable removes all cases in our data in which wages increase after households move to a higher paying job. We keep the relocation pressure dummy $D_{i t}$ from the previous specification to allow for the possibility that wages can have a different effect on the propensity to move for households who plan to relocate. For instance, cash constrained households that intend to move will respond more strongly to rising wages than households that face no relocation pressure. Like before, we separately estimate two regressions for tenants and owners. We expect tenants to have a higher mobility and to respond more strongly to wages due to their lower average income levels and lower overall financial wealth. In contrast to the previous regression on house prices, the impact from wages is ambiguous. On the one hand, households that experience severe labor market pressure may relocate to areas with less competition where their income is still sufficient to afford appropriate accommodation. Given that Switzerland is a small country with a well-functioning public transportation system, labor markets are often spatially dispersed. On the other hand, moving is costly and cash constrained households may be faced with affordability restrictions when wages decrease. Which effect dominates is an empirical question that we explore in section 4.

\subsection{Sentiment based relocation pressure}

We have identified house prices and wages as two important channels through which largescale immigration affects the incumbent population. Although we consider these channels to be the main indirect effects from immigration, we should also consider the possibility that incumbent 
households directly respond to the presence of immigrants. This direct effect includes households' expectation about future house price and wage changes but also preferences for ethnic neighborhood composition (Logan and Zhang, 2010). In other words, we are interested in the direct effects of immigration on incumbent households once we control for changes in house prices and labor income. We therefore interpret the result as a "residual" or "sentiment" effect. In our model overview in Figure 1, the underlying specification is denoted as model III. The following specification estimates the fraction of immigration induced relocation that can be attributed to the sentiment effect:

$$
\Delta \text { Swiss }_{t}^{r}=\alpha_{1} O E C D_{3 y r}^{r}+\alpha_{2} \text { RoW }_{3 y r}^{r}+\alpha_{3} H P_{t}^{r}+\alpha_{4} W_{i t}+\alpha_{5}^{\prime} \text { controls }+\varepsilon_{t}^{r}
$$

Eq.(5) estimates the percentage change in the native population measured on the aggregate municipality level. One advantage of the aggregate model is that inference can be based on more than 44,000 observations. In contrast, the individual household level regressions suffer from a general low mobility of households, with only $7 \%$ or 1,397 households moving over the entire sample periods. The empirical findings from the aggregate model therefore complement the more granular household level regression by adding transparency and robustness.

The household level specification is similar but uses the probability to move as the dependent variable. As a consequence, negative coefficients $\alpha_{1}$ and $\alpha_{2}$ in Eq.(5) indicate a decrease in the number of incumbent Swiss households, but positive coefficients $\beta_{1}$ and $\beta_{2}$ denote an increase in the probability to move.

$$
\text { Move }_{i t}^{\text {tenant/owner }}=\beta_{1} O E C D_{3 y r}^{r}+\beta_{2} R_{0} W_{3 y r}^{r}+\beta_{3} H P_{t}^{r}+\beta_{4} W_{i t}+\beta_{5}^{\prime} \text { controls }+\varepsilon_{i t}^{r}
$$

Like before, we estimate Eq.(6) as two separate regressions where house prices $H P_{t}^{r}$ are replaced by rents Rentr in the tenant regression. With house prices and wages explicitly accounted for, we can interpret the coefficients $\beta_{1}$ and $\beta_{2}$ as the sentiment effect from OECD and rest-ofworld immigration. In the following section, we will present the data that is used in the empirical part of the paper.

\section{Data}

In this study, we combine data for Switzerland from four distinct sources. Three sources are government agencies and one is a private research and consulting firm. Some of the variables are 
measured on the aggregate municipality level, while others are available for individual households. Information on the number of immigrants is provided by the Swiss Federal Statistical Office (Bundesamt für Statistik) on an annual basis between 1991 and 2013. Average wages per municipality are obtained from the Swiss federal tax authority (Eidgenössische Steuerverwaltung). Transaction level house prices and rents are obtained from the Zurich based company Fahrländer Partner Raumentwicklung. Finally, we observe relocation decisions of individual households based on survey data from the Swiss Household Panel, administered by FORS at the university of Lausanne.

\subsection{Immigration Data}

The Swiss Federal Statistical Office (Bundesamt für Statistik, BFS) collects information on every immigrant arriving in Switzerland from 1991 to 2013. Our database consequently holds over 15-million individual immigration and emigration entries. The data contains information on firsttime arrivals, departures, as well as the movements of foreigners within Switzerland. The data also records the numbers of native Swiss households per municipality. This information is important to place the absolute immigration numbers into economic context.

According to numbers published by the OECD, Switzerland has the highest rate of immigration in Europe. As a consequence, the share of foreigners, currently $24 \%$ is also among the highest (OECD, 2015). ${ }^{13}$ An important aspect for our paper is the high degree of heterogeneity in the composition of immigrants. We find a high variation in the size of the estimated impacts from immigration, depending on the home country of arriving immigrants. Figure 2 shows the net immigration flows over our sample period. In the early 1990s, numbers have been dominated by a large inflow of immigrants from former Yugoslavia who arrived as refugees during the Balkan wars. ${ }^{14}$ In contrast, many high skilled immigrants from Germany have been attracted by high wages and living standards in more recent years. These two immigrant groups differ with respect to skills and education, the wages they earn on the labor market, and hence also their potential to affect real estate prices and rents.

${ }^{13} \mathrm{https}$ ://stats.oecd.org/Index.aspx?DataSetCode=MIG. To put these numbers into context, neighboring Austria and Germany had foreigner shares of $14 \%$ and $12 \%$ over the same period

${ }^{14}$ Immigrants from former Yugoslavia declared "Yugoslavia" as their home country until 1998 after which the main source countries are Serbia, Montenegro, and Madeconia. On a smaller scale, immigration also occurred from Bosnia and Herzegovina, Croatia, Kosovo, and Slovenia. 
$<<$ Figure 2 about here $>>$

The BFS tracks a number demographic characteristics for each immigrant: date of birth, year of arrival including the year of movement within Switzerland, gender, country of origin, type of residency permit, and the municipality in which the person is registered. Given that we have 2,323 municipalities and cover 22 years, we have a minimum of 51,106 panel observations.

Switzerland defines several categories of permits at the federal level. The B-category denotes people who have been given a work or study permit for 5 years. In our sample, $42 \%$ of first-time arrivals, who have never lived in Switzerland, received this type of permit. These immigrants are unlikely to buy real estate but will likely compete on the rental market for attractive properties. Since the value of a property is defined by the present value of future rental streams, activity on the rental market will also affect house prices indirectly. Persons with a C-category $(20 \%$ of immigrants) are long-term residents who have an unconditional right to remain in Switzerland. Some people with a C-category do buy properties. L-permits are given to persons who work in Switzerland for less than a year. This category of permit is still active and is typically given to immigrants from beyond the EU. Categories N, S and F, as well as several other categories for short-term residents, are given to refugees and other arrivals looking for asylum in Switzerland. In our sample the categories L, N, S, and F sum to almost $30 \%$ of our sample. In the empirical part of this paper, we find evidence that the type of residency permit has an important impact on house prices and rents.

Figure 3 shows total immigration numbers. Panel A shows the number of immigrants by country of origin measured in 1,000 persons. The two largest groups of immigrants come from Germany with a net immigration of 211,000 persons and from former Yugoslavia with a net immigration of 189,000 persons. These net immigration figures are the balance of much larger flows. The gross inflow from Germany over the 22-year period was over 1 million immigrants while the gross outflow summed to 841,000 persons. To put these numbers into economic context, the last column of Panel A shows net immigration numbers as a percentage of the native Swiss population. For instance, the total net immigration over the period $1992-2013$ amounts to almost $15 \%$ of the local population. Depending on the ability to consume housing and the absorption capacities of the local real estate and labor market, these immigration flows are likely to have 
substantial impacts on property prices, rents, and wages. ${ }^{15}$ In Panel B we look at the regional distribution of immigration. The major metropolitan municipalities Zurich, Geneva, and Lausanne receive large parts of the immigration flows. Empirical results based on absolute immigration numbers would therefore be dominated by major cities. The same number of immigrants can be easily absorbed into the housing markets of large cities but would have a significant price effect in small towns. To address this issue, we divide the number of immigrants by the Swiss population in that municipality. Panel $\mathrm{C}$ show immigration measured in this way. In contrast to the graph in Panel B in which immigration was averaged over time, Panel C shows every individual observation across time and municipality. Panel $\mathrm{C}$ highlights that in some municipalities the immigration flows are extremely large relative to the local Swiss population. For instance, a number of regions that are attractive tourist locations have seen large inflows of immigrants that work in the tourism and service industry for a few months per year. To mitigate the influence of these observations we winsorize at $15 \%$ of local Swiss population. ${ }^{16}$ This affects only $3.5 \%$ of our observations and has little impact on our empirical results. However, the overall immigration distribution becomes more homogeneous.

\section{$<<$ Figure 3 about here $>>$}

Throughout the paper, we have referred to immigration as "push immigration". We thereby aim to capture the exogenous part of immigration that generates incentives to leave or to get "pushed" out of the home country. This stands in contrast to economic developments and job opportunities of a region within Switzerland that attract and thereby "pull" immigrants into a region. Since pull factors are likely to be endogenous to change in house prices and wages, we use only the push components as a measure of exogenous immigration. The underlying methodology was first developed by Card (2001) and used in the Swiss context by Basten and Koch (2015). It starts with the empirical observation that early migrants facilitate the transition for later arrivals by providing a familiar environment and offering advice on how to find jobs and housing (Massey et al., 1987; Bartel, 1989; Munshi, 2003). As a consequence, new arrivals tend to migrate to certain areas where the concentration of other immigrants from the same ethnic background is high. This behavior can be regarded as exogenous because it is not driven by economic development in any

${ }^{15}$ Another noteworthy observation from the data is that the largest group of arrivals are in prime working-age, i.e. between 25 and 35 .

${ }^{16}$ A cap of $15 \%$ corresponds to two standard deviations from the mean. 
particular region. Applying this idea to the data, we take the total immigrants of a particular nationality in a given year and manually distribute these to each municipality according to the share of immigrants from that nationality that lived in the area a number of years ago. We take the actual immigration numbers for the entire country but generate municipality level immigration numbers that differ from the actual numbers for each municipality. Thus, we generate immigration numbers that measure how immigration would occur in each municipality if it was entirely driven by the exogenous factor "past share of people from a certain nationality living in a region". To construct historical shares, we make use of historical immigration rates from 1991 to 1993. In Appendix A of the paper, we compare actual and pushed immigration for selected regions and show that they generally share a high degree of comovement. An example may help to illustrate the concept. The actual number of German immigrants moving to Zurich City in 2010 was 4,688. However, the share of Germans moving to Zurich City was lower in 1990 than in 2010. Using historic distribution of immigrants, we therefore allocate only 3,574 immigrants to Zurich from Germany. The remaining 1,114 are distributed to other regions that were more popular among German immigrants in the early 1990s.

\subsection{Municipality Level Wage Data}

The Swiss federal tax authority collects detailed wage data for individual households in order to compute the tax burden. Unfortunately, this data is highly sensitive and generally not available for research. However, we obtained average wages, computed for each municipality in Switzerland over the period from 1993 to 2014. We have access to both mean and median wages, focusing on the median in the empirical part below to avoid distortions from a few high net-worth individuals.

\subsection{Swiss Real Estate Prices and Rents}

Residential property prices and rents are provided by Fahrländer Partner Raumentwicklung (FPRE). The data contains annual observations from 1992 to 2013 for all municipalities in Switzerland. Over time, a number of municipalities have merged and new ones have formed. We focus on a current map from 2015 covering 2,323 municipalities. The prices provided to us are based on actual sales data, combined with a hedonic pricing model developed by Fahrländer (2006, 2008). Figure 4 shows the spatial distribution of house price levels and growth rates across the 2,323 municipalities. Panel A shows the log house price levels in 2015. One observation that follows from Panel A is the concentration of high price regions in and around agglomeration centers such as Zurich, Basel and Geneva. For instance, average log CHF house prices in Zurich are 14.66 
(approximately EUR 2,150,000). These regions also experience above average price growth since 1992. ${ }^{17}$ Panel B shows house price growth rates for the period 1992-2015. Areas shaded in dark red indicate overall growth rates of $100 \%$ and more. From Panel B we can see that the most expensive regions in Switzerland have also experienced the highest growth rates over the last 24 years.

\section{$<<$ Figure 4 about here $>>$}

With a homeownership of only $44 \%$, Switzerland has a large rental market. ${ }^{18}$ Tenants respond differently to changes in real estate markets than owners, and most immigrants are likely to rent rather than buy in their year of arrival. FPRE provides historical data at the municipality level for single family homes and apartment rents starting from 2008. For earlier years, rents are only available at the MS region level, which are slightly more aggregated than the municipalities (106 MS regions vs 2,323 municipalities). We impute missing rents at the municipality level using fitted values from regressions of MS region rents on a dynamic structure of municipality-level house prices and different house price tiers.

Finally, we compute the vacancy rate as the number of empty houses divided by the total number of houses in each municipality. Regions with a significant stock of empty houses can more easily absorb an inflow of immigrants and should therefore show smaller property price responses than regions with no excess capacity.

\subsection{Household Panel Data}

We use survey data from the Swiss Household Panel (SHP) to estimate the response of individual households to changes in local property prices, rents, wages, and immigration. Investigating individual households allows us to measure not only the overall response for a municipality, but to observe which households are affected and by how much. Household-level data also has the advantage that individual observations are too small to generate feedback effects, for instance from relocation back to house prices or wages. The SHP is based on surveys administered by FORS in Lausanne and covers the years 1999 to 2014. In contrast to the municipality level data described in the previous subsections which covered more years from 1992

\footnotetext{
${ }^{17}$ For instance, nominal CHF house prices across Switzerland increased on average by 57\% from 1992 to 2015.
} During this period, house prices in Geneva almost tripled and those in Zurich and Basel doubled.

${ }^{18}$ For historical data on the homeownership rate in Switzerland see https://tradingeconomics.com/switzerland/ home-ownership-rate 
to 2013, our empirical estimates based on individual households are based on this somewhat smaller sample. The survey gathers information on the specific location of a household, whether the households is a tenant or owner, as well as some basic indicative data on socioeconomic characteristics. These include household composition as well as information about the size and the source of income. ${ }^{19}$ The SHP data has several advantages. First, it has a very high retention rate: households appear in the survey for an average of more than six years. A high retention rate allows us to control for household level fixed effects as well as time-varying aspects of a household's composition in regression specifications. It is important to see, for instance, whether households change their behavior following a "life-changing event" such as the birth of a new child, divorce, or death of a family member. Moreover, we are able to explain the observed heterogeneity across different subsamples, as households are more likely to respond to changes in property prices or wages following a shock to income, expenses, or housing needs.

Table 2 shows summary statistics for a number of variables pertaining to household location and tenure choice. The table is based on over 51,000 individual household-year observations. Given that relocation is a significant contributor to respondent attrition in surveys, the numbers presented in the table should be viewed as conservative. Panel A shows how the relocation behavior and tenure choice of households differs for high and low immigration municipalities. We denote a municipality as a high immigration area if the net immigration flow over our sample period is above the median. Panel A suggests that households are more likely to move and less likely to own a home if they are located in a high immigration area. ${ }^{20}$ This could be interpreted as first evidence in favor of a displacement effect.

\section{$<<$ Table 2 about here $>>$}

Panel B shows a number of socioeconomic characteristics for households that move. On average, movers tend to be younger, better educated, and have higher incomes compared to nonmovers. In the next section, we investigate the relationship between immigration, house prices, wages, and household's relocation decisions in a more formal empirical framework.

${ }^{19}$ One problem that can arise when tracking household financial information through self-reported surveys is that households may misreport data (Pissarides and Weber, 1989). However, we believe that the benefits that come with the important information on household behavior more than compensates for these potential shortcomings.

20 The ownership rate in our sample is $40 \%$, which is comparable to the Swiss average of $44 \%$, see https://tradingeconomics.com/switzerland/home-ownership-rate. 
4. Empirical FindingsIn this section, we interpret our empirical findings concerning the impact of large-scale immigration to Switzerland. We place particular emphasis on the joint analysis of aggregate and individual household level results. While our findings from household level regressions generally support the aggregate municipality level estimates, they also reveal economically important differences that can be explained by variation in household characteristics. Some of our results confirm findings that have been previously reported for other countries. Others, like the effects of immigration on displacement, are different from the existing literature and add new insights to the topic. This section follows the structure from section 2: First, we report the findings concerning the effects of immigration on house prices and wages (model I). Second, we show how house prices and wages can serve as a transmission channel to cause displacement of incumbent households (model II). Finally, we show that immigration also has an economically large direct effect on displacement, which we interpret as a residual or sentiment effect (model III). Table 3 summarizes this structure and shows the estimating equations that are used to identify the economic channels. The equations in this table are taken from section 2, but show the complete specification including the full set of control variables. For instance, municipality level regressions include a spatial lag $\rho\left(W_{N} \otimes I_{T}\right)$ that allows for a more realistic dissemination of shocks to nearby regions. Household level regressions control for a number of time-varying household characteristics including the level of education, age, and the number of children.

$$
<<\text { Table } 3 \text { about here }>>
$$

The last column of Table 3 indicates whether the regression was estimated using aggregate municipality level data or more detailed data based on individual households. If possible, we include both specification to show the overall effects as well as the heterogeneous responses among individual households.

\subsection{The Effects of Immigration on House Prices and Wages}

Table 4 shows the house price impact from a 1 percentage point increase in new immigrants. The house price response is estimated across 2,323 Swiss municipalities over 22 years resulting in 51,106 total observations. Panel A shows standard OLS estimates. A one percentage point increase in the share of foreigners from Western Europe and OECD countries increases house prices on average by $2.87 \%$. The same increase coming from Rest of World immigrants is estimated to be $1.01 \%$ and is therefore only one third of the size. The difference in coefficients is in line with the 
notion that the first group tends to be better educated, has more financial wealth, and hence, has a higher demand for housing space. ${ }^{21}$ A $1 \%$-pt. increase in the vacancy rate lowers house prices on average by $0.29 \%$.

$$
<<\text { Table } 4 \text { about here }>>
$$

In recent years, the spatial regression model appears to have replaced the ordinary least squares method as the canonical methodology for dealing with real estate data (LeSage and Pace, 2009; Elhorst, 2014; LeSage and Chih, 2016). A major drawback of OLS estimates is that the entire response is assumed to occur within the shock originating municipality but drops to zero when crossing the border into the neighboring municipalities. In practice, however, we can observe that shocks easily transmit to neighboring regions so that the house price response is somewhat lower in the shock originating region compared to OLS, but larger overall when neighboring municipalities are taken into account. Panel B, shows exactly this behavior. We reestimate the same equation using a panel spatial autoregressive (SAR) model (LeSage and Pace, 2009). The estimate of the spatial lag indicates that house prices in one region are $82 \%$ of the average house prices in the six nearest neighboring regions. This suggest a very strong spatial dependence structure and a pronounced spatial diffusion of shocks. In the spatial model, a 1\%-pt. increase in the share of foreigners from Western Europe and OECD countries in a specific region $i$ increases house prices on average by $1.15 \%$ in the same region $i$. The coefficient is less than half of the OLS estimate, which is a typical finding for spatial models since the total effect is now distributed over several regions. For instance, it increases house prices in the long run by $0.39 \%$ in municipalities that are first-order neighbors, and by $0.18 \%$ in second-order neighbors. Due to feedback effects from neighboring municipalities, house prices in region $i$ also increase by $1.43 \%$ in the long run. ${ }^{22}$ Like before, the house price response from Rest of World immigrants is somewhat muted. The results mask a high degree of heterogeneity within the constituent countries of each group. In Appendix

${ }^{21}$ The house price changes estimated here should be regarded as conservative since some incumbent households might react immediately to the arrival of immigrants (Hatton, 2005). This could drive house prices down and bias our price estimates towards zero. Running a similar regression using rents instead of prices as the dependent variable gives comparable results. For instance, the coefficient for immigration from Western Europe and OECD countries is 1.42, and for immigration from RoW countries is 0.40 .

22 The panel SAR model is a static model so that the concept of "long run" is not well defined. Since the economic mechanism behind spatial price diffusion depends on the price elasticity and the mobility of households, long-run effects are likely to take 5 to 10 years (see also Fitzgerald (1999) and Thornton (2011)). 
B of this paper, we discuss the spatial panel model in more detail and show a table of the house price effect for individual countries. One interesting finding from the table in Appendix B is that immigration from Germany has a much lower house price effect than might be expected (0.16), and that immigrants from some countries such as Italy and Turkey even have negative estimates (0.29 and -0.43 respectively). In summary, the SAR estimates in Panel B are more likely to reflect the true house price response given that they accommodate a more realistic spatial interaction. The spatial model also fits the data better as indicated by the higher R-squared ${ }^{23}$.

Our findings concerning the impact of immigration clearly points to a positive house price effect. In contrast, the effect on wages is more elaborate and varies substantial for individual households. Table 5 shows the aggregate municipality level effect of immigration on wages. We measure wages as the average income per municipality. Panel A shows the benchmark OLS estimates which indicate that immigration from Western Europe and OECD countries has a positive effect on wages whereas Rest of World immigration is estimated to have a negative impact. In particular, a 1\%-pt. increase in immigration from Western Europe and OECD countries increases wages on average by $1.09 \%$ while the same increase in immigration from RoW countries lowers wages by $0.57 \%$. A wage decrease of $0.57 \%$ is about half of what Peri and Sparber (2009) estimated for the U.S. in case of perfect native-immigrant substitution, indicating that immigrants and Swiss workers specialize in different production tasks, thereby reducing downward wage pressure. This is confirmed in a recent paper by Beerli and Peri (2017) who examine the wage effects of crossborder workers in Switzerland and find a high degree of complementarity.

$<<$ Table 5 about here $>>$

Panel B of Table 5 shows the coefficient estimates of the same model using a spatial autoregressive (SAR) model. Hatton et al. (2005) note that in empirical work, the wage effect of immigration is often measured to be unexpectedly low because most studies ignore that fact that local workers are displaced so that the total wage effect is spread out over several regions. The coefficients in Panel B accommodate for the spatial dissemination of the wage effect. For instance, a 1\%-pt. increase in immigration from Western Europe and OECD countries increases wages in the immigration municipality by $0.79 \%$ within the same year, and by $0.91 \%$ in the long run. The spatial dissemination of wages is weaker than that of house prices (spatial lag is 0.45 for wages

${ }^{23}$ The R-squared values reported in this and the following tables are based on regressions in which the coefficients of both, municipality and year fixed effects are estimated. The R-squared on demeaned data is much lower. 
versus 0.82 for house prices). Still, wage changes are estimated to have economically significant spillovers.

While the municipality level estimates show important aggregate wage changes, they cannot show the large heterogeneity in the wage response on the household level. Some households will compete with immigrant on the labor market while others benefit from the additional demand for goods and service that new inflows of immigrants generate. Panel A of Table 6 shows the wage response to immigration for individual households where we distinguish between tenants and owners. ${ }^{24}$ This split also separates households by a number of other characteristics such as income, wealth, and wage brackets. ${ }^{25}$ The coefficients in Panel A show important differences to our previous aggregate estimates. For instance, immigration from Western Europe and OECD countries was shown to have positive wage effects on aggregate, but is estimated to have no significant impact on tenants and a negative $1.67 \%$ impact on owner households.

$$
<<\text { Table } 6 \text { about here }>>
$$

At first glance, our results for individual household are difficult to reconcile with our aggregate estimates obtained before. However, they are in line with previous findings from Ottaviano and Peri (2012) who demonstrate that immigration leads to some degree of substitutability between natives and immigrants but at the same time can have complementary effects with the wages of other natives so that the overall wage response differs strongly across households. To illustrate this point, Panel B of Table 6 shows the estimated wage coefficients for different wage quantiles. These quantile regression coefficients measure the degree to which different income groups are affected by immigration from Western Europe and OECD countries (red line) and RoW countries (blue line). The wage coefficients for tenants (left graph) show that wages of low income households respond much more to immigration than the average household whereas medium and high income households show much smaller wage sensitivities to immigration. In particular, wages of low income tenants increase in response to immigration from Western Europe and OECD countries. This is in line with the idea that high-skilled immigrants increase the demand for low-skill intensive services such as hospitality, restaurant, and food services (Beerli and Peri, 2017) often opening opportunities for entrepreneurship (see e.g. Rath and

${ }^{24}$ We measure wage as the self-reported labor income recorded in the Swiss household panel. We take the income of both respondents in a two-person household and the income of one respondent in a single person household.

${ }^{25}$ See Blickle and Brown (2016) for an extended discussion of the socioeconomic differences between initial renters and owners. 
Kloosterman, 2000, and Zelekha, 2013). In contrast, immigrants from the Rest of World countries are likely to enter into direct labor market competition with tenants, while leaving the wages of high income tenants and owners unaffected. The wage response of owner households (right graph) is more negative than that of tenants. On the one hand, owners are likely to be wealthier and have higher average incomes than tenants (middle graph). ${ }^{26}$ On the other hand, they are also likely to be less mobile (the unconditional probability to move is $6.9 \%$ for tenants, but only $3 \%$ for owners) and therefore more exposed to immigration induced local labor market competition. To sum up, the wage changes experienced by individual households can differ considerably from the aggregate level effect, depending on whether the household is employed in the same sector as the immigrants, leading to partial substitution, and whether there are complementary effects from immigration, in which case the wage effects can be positive. ${ }^{27}$ This can also explain why many households view new immigrants as potential competitors despite the overall positive effect. The degree to which economic decision making by native households is driven by perceived immigration effects and sentiment is an important issue in our study that we will return to below.

\subsection{Immigration and Displacement}

In the previous section, we have presented empirical evidence that immigration affects house prices and wages. In this section, we examine the response of the incumbent population to these changes. We are interested in the role of housing and labor markets as transmission channels of immigration. We find that both, house price growth and income shocks affect the propensity of native households to relocate to a new region. In case of house price and rent changes, we have to take the particular regulatory environment into account under which these changes occur.

Table 7 shows the potential of rising house prices to generate relocation pressure for individual households. Like before, we run separate regressions for tenants and owners. Panel A

${ }^{26}$ The average annual gross income of tenant households in our sample is CHF 103,539, while that of owners is $20 \%$ higher at CHF 124,396 .

${ }^{27}$ A recent related study on cross-border workers and wages in Switzerland is Beerli and Peri (2017). They find a positive effect for wages of high skilled native households following an increase in high-skilled cross-border workers. They explain this observation by complementarity effects that allow Swiss native households to upgrade to higher positions. We cannot confirm this complementarity effect for our study but note that in contrast to our paper, the focus of their study is on cross-border workers who commute to Switzerland on working days but live and spend their income in a different country. This is different from our study which investigates the effect of mainly long-term immigrants. 
shows the effects of a one percent increase in rents when the dependent variable is a binary relocation variable in the tenant regression, and it shows the effects of a $1 \%$ increase in house prices in case the household is an owner. As discussed in section 2, the response for individual households will differ depending on their relocation pressure and intend to move. ${ }^{28}$ For instance, a one percent increase in rents reduces the likelihood that tenants will move to a new municipality by 0.054 percentage points. Since existing rent contracts provide full protection against rent increases, current tenants will not be affected by higher market rents. In contrast, tenants with a preexisting need for a new home will need to pay the higher current market rate in that municipality and are therefore 0.05 percentage points more likely to move to a new municipality then tenants without relocation pressure. ${ }^{29}$

\section{$<<$ Table 7 about here $>>$}

In the regressions for owner-occupied houses, we find that a one percent increase in house prices decreases the propensity to move by 0.018 percentage points. Like tenants, homeowners prefer not to move if housing costs increase in their municipality. In contrast, a preexisting relocation pressure increases the propensity to relocate by $0.026(0.047-0.021)$ percentage points.

A drawback of our interpretation so far is the fact that the marginal effects in our model differ across variables in terms of size and dimension. For instance, net immigration shocks are measured as a one percentage point increase while house price and wage shocks are measured as a one percent increase. The economic size of a one percentage point increase in net immigration is considerably larger than the economic size of a one percent increases in house prices or rents. To facilitate the comparison of shocks across variables, Panel B of shows the response in the propensity to relocate to a one standard deviation shock. For instance, a one standard deviation increase in rents (which corresponds to an annual increases of CHF 2,249, or about EUR 1,930) decreases the propensity to move to a new area by $0.53 \%$-pts for households without relocation pressure. On the other hand, a one standard deviation increase in house prices (CHF 172,306)

${ }^{28}$ Relocation pressure may be induced by marriage, birth of a child, divorce, or death of a household member.

${ }^{29}$ By construction, households with a preexisting desire to move have a higher unconditional propensity to relocate. The $0.05 \%$-pts. denote the sensitivity of these household to changes in rents. 
increases the propensity that homeowners relocate by $0.33 \%$-pts. ${ }^{30}$ The results from Panel B suggest economically large relocation responses from typical house price movements: homeowners' unconditional probability to move is $3 \%$ so that an increase of $0.33 \%$-pts. translates to a $11 \%$ higher relocation probability.

Ultimately, we are not interested in the house price effect in isolation but as a transmission channel of immigration. In Panel C, we show the relocation response from a one standard deviation increase in net immigration from Western Europe and OECD countries. To obtain these indirect effects, we multiply three coefficients: (1) the standard deviation of net immigration, (2) the house price response from net immigration (see Table 4), and (3) the propensity to move coefficient from Panel A. As a results, we measure how a one standard deviation increase in immigration affects house prices and how this house price increase in turn affects the propensity to move. One standard deviation in immigration corresponds to 0.59 percentage points. ${ }^{31}$ From our findings in Table 4 above we know that a one percentage point increase in immigration translates into a $1.15 \%$ increase in house prices. According to our estimates, a one s.d. increase in net immigration will therefore decrease the propensity to move on average by $0.012 \%$-pts., but has a positive $0.012 \%$-pts. impact for households with a preexisting relocation pressure. ${ }^{32}$

The economic size of the coefficients reported in Table 7 varies considerably and requires some comments. While the direct effects from housing costs are economically large, the indirect effects from immigration are almost negligible. This does not mean that immigration is not an important driver of relocation decisions. But it shows that house prices, although playing an important role by themselves, are not an important transmission channel for the effects of immigration. The pass-through from immigration to house prices is simply not large enough to affect the propensity to move in this way. Our conclusion from Table 7 is that the housing market

${ }^{30} 0.47-0.14=0.33$. Since the regression specification in Table 7 includes household fixed effects, the standard deviations are also estimated on the household-demeaned data. Time fixed-effects are not included in the model because of perfect multicollinearity with included time-varying household characteristics such as age.

31 The house price effects from immigration are estimated in a two-way panel regression. Hence, the one standard deviation number ( 0.59 pct.pts.) is also from double demeaned data.

32 The coefficient estimate for the short-run effect was 1.15 so that a one s.d. shock in net immigration from Western Europe and OECD countries (which equals 0.59 percentage points) increases the relocation pressure of owners by $0.59 \times 1.15 \times(0.031-0.014)=0.012 \%$-pts. 
is important for relocation decisions, but that the role of house prices as a channel for immigration is limited.

In Table 8, we turn to the investigation of labor income. Panel A shows that tenants respond positively to an increase in income. Homeowners, which tend to be less cash constraint, appear less affected. For tenants, a $1 \%$ increase in wages increases the propensity to move by 0.016 percentagepoints. For tenant households who have indicated that they intend to move, this effect grows to 0.053 percentage-points. A positive impact from wages indicates that households upgrade to larger and higher quality homes following a positive income shock. In addition, a positive coefficient can be explained by the fact that moving to a new municipality involves social but also considerable monetary costs. Although a response in the order of 0.053 pct.-points is fairly small in absolute terms, it indicates that cash constraint households may be forced to retain "locked-in" rents that lie below current market rates. As a consequence, tenants are more likely to move when additional resources become available. Since household relocation enters the regression with a lead of one year, we can rule out the reverse causality case in which households move because of a betterpaying job. An implication that follows from the estimates in Panel A is that lower wages decrease the propensity to move, possibly because a new accommodation would be difficult to afford. The positive effects from lower household income therefore seem to outweigh potential negative effects that result from dissatisfaction when households experience lower incomes.

$$
<<\text { Table } 8 \text { about here }>>
$$

To put the coefficients into economic context, Panel B reports the relocation response following a one standard deviation increase in wages. A one standard deviation increase corresponds to CHF 56,861, or about EUR 49,000. Tenants are 0.6 percentage-points more likely to move following a one standard deviation increase in wages and even 2.0 percentage-points if they intend to move. These findings suggest that household income can serve as a strong motivator in the decision process to relocate to a new municipality.

Finally, Panel $\mathrm{C}$ shows the indirect effect of income when the source of change is a one standard deviation increase in immigration from Western Europe and OECD countries. A one standard deviation change corresponds to a 0.59 percentage-point increase in immigration which in turn incentivizes households to relocate via the wage channel. We find that a 0.59 percentagepoint increase in immigration increases the income of tenants by $0.46 \%$ which in turn increases the propensity to relocate by $0.46^{*} 0.016$ percentage-points or 0.007 pct.-points. One of our main 
findings from the analysis of immigration on wages was that tenants and owners respond differently to immigration. This would mean that a comparable increase in immigration from RoW countries would predict an effect in the opposite direction. For instance, a one pct.-point increase in RoW immigration is estimated to decrease labor income for tenants by $0.38 \%$ (see Table 5) which in turn lowers the propensity to relocate by $0.38 * 0.016$ or 0.006 pct.-points. To conclude, we find that both house prices and wages can have economically large effects on the relocation decisions of households but that their role as transmission channels from immigration is negligible.

\subsection{The Sentiment Effect}

The empirical evidence presented so far shows limited pass-through from housing and labor markets. In this section, we estimate the direct effects from immigration on the propensity to move, controlling for house prices, rents, and wages. A direct relocation effect implies that households do not move because of the changes that result from immigration but because of the presence of immigrants themselves. In Figure 1, this situation was illustrated as "model III". In this setup, house prices and wages no longer take the role as transmission channels but are simple control variables. For instance, households may have a preference for neighborhood composition (Bruch and Mare, 2006; Logan and Zhang, 2010). Another reason for our findings may be that households form expectations about the future development of house prices and wages. Although the direct impact of immigration on real estate and labor markets may be initially small, households are likely to anticipate the long-term effects of immigration. ${ }^{33}$ In addition, households may feel under pressure on the housing market and may be concerned about growing competition on labor markets even when if their fears are unfounded. As a consequence, expectations about future changes may lead households to relocate themselves ex-ante. We interpret the combined effect from perceptions, preferences, and expectations as a variable that is uncorrelated with our measures for housing and labor market outcomes and that reflects household's "sentiments".

Household mobility is low in Switzerland. The majority of households (72\%) never move over the entire sample period from 1999 to 2014. Household-level results are therefore based on only 1,754 individual households. While this number allows for meaningful inference, we can avoid small sample bias by examining aggregate municipality level flows of incumbent

\footnotetext{
${ }^{33}$ An implicit assumption of this argument is that household's expectations are less than perfectly correlated with actual house price changes so that these expectations enter the model as a separate sentiment variable.
} 
households. Table 9 shows the annual change in the local Swiss population following a one percentage point increase in immigration. ${ }^{34}$ Annual movements of the local Swiss population are based on 2,323 municipalities over 19 years or 44,137 observations. The results in Table 9 show a decline in the incumbent population following an inflow of immigrants. In particular, a one percentage point increase in net immigration from Western Europe and OECD countries leads to a $0.37 \%$ outflow of the Swiss population. The findings are in line with those estimated for U.S. studies. For instance, Borjas (2006) reports roughly 3 natives displaced for every 10 immigrants. SAR based estimates are somewhat lower but lead to the same conclusion. Interestingly, the coefficients for immigration from rest of world countries is not significant. Although our findings in Table 9 cannot reveal the extent to which relocation decisions are driven by household characteristics, they are quite suggestive of the economically large response of the incumbent population.

$<<$ Table 9 about here $>>$

Household-level relocation effects are shown in Table 10. Panel A shows the impact from a $1 \%$ increase in net immigration using house prices, rents and wages as control variables. Panel A shows that tenants are about 1 percentage point more likely to move following a one percentage point increase in immigration from Western Europe and OECD countries. The findings for individual households therefore confirm our previous aggregate-level results from the previous table. However, Panel A also shows two new results that were masked by previous aggregate estimates. First, immigration from rest of world countries also induces relocation pressure, but only for owners. Second, relocation is much more likely if households already have a preexisting pressure to move. For instance, a one percentage point increase in net immigration from rest of world countries increases owner's propensity to move by 0.486 percentage points. With preexisting relocation pressure, this effect grows to 1.001 percentage points.

$$
<<\text { Table } 10 \text { about here }>>
$$

The sentiment based relocation coefficients are 40 to 100 times large than our previously reported housing and labor market effects. However, this comparison ignores the fact that immigration changes by one percentage point which is economically large compared to a one percent increase in wages. Panel B facilitates comparison by converting the shocks into one

\footnotetext{
34 The "Swiss" population in a municipality is defined as all residents with Swiss citizenship.
} 
standard deviation. The coefficients in Panel B are comparable to those found for one standard deviation effects of house prices and wages. For instance, a one standard deviation effect for homeowners with preexisting relocation pressure is 0.33 percentage points for house prices, 0.95 pct.-pts. for wages, and 0.75 pct.-pts. for rest of world immigrants. An important result from this section is therefore that (i) housing markets, labor markets, and immigration induce similar displacement effects on Swiss households, but that (ii) housing markets and labor markets are not important transmission channels of immigration. Instead, the displacement effect from immigration is direct.

The empirical evidence on the displacement effects of immigration was dispersed over three tables each featuring different sub-panels. In Figure 5 we summarize these findings in a compact way. We distinguish between tenant households (left graph) and homeowners (right graph). Within each graph, we further group by immigration type and preexisting relocation pressure.

$<<$ Figure 5 about here $>>$

The blue bars show the unconditional propensity to move which is $6.9 \%$ for tenants and $2.9 \%$ for owners. By construction, the unconditional propensity is higher if households intend to move (9.2\% for tenants and $3.9 \%$ for owners). The red bars show the increase in the propensity to move from a one standard deviation increase in net immigration. In every graph, the first bar denotes the housing market channel of immigration, the second bar denotes the direct immigration effect, and the third bar indicates the wage channel of immigration. The red bars show the long-run SAR coefficients that are obtained from summing over all regions. ${ }^{35}$ Figure 5 highlights the economic size of the coefficients and confirms our previous findings: immigration affects household relocation decisions directly. Housing and labor markets have economically insignificant effects and are unlikely to serve as important transmission channels of immigration.

\subsection{Immigration and Satisfaction}

For many households, leaving a familiar environment and relocating to a new region involves high social costs. Concerns and discomfort caused by immigration is generally unlikely to provoke large relocation responses. The empirical results in this paper have shown that a preexisting

35 The SAR coefficients shown in the Table 6, 7, and 9 denote the short-run effects in the immigration municipality. These effects ignore the additional impact that follow from the dissemination to neighboring regions. The long-run coefficients presented here in Figure 6 correct for this. 
relocation pressure is an important factor to cause households to decide that relocating is in their best interest. However, the Swiss household panel does contain a number of complaint items related to the accommodation and the neighborhood of a household. For many households who decide that moving does not sufficiently compensate for the costs, immigration is likely to be reflected in their general satisfaction level. In Figure 6, we provide empirical evidence that is in line with this notion. Panel A shows the estimated increase in probability that an incumbent household reports a complaint following a one percentage point increase in net immigration over the previous three years. Blue bars denote regression coefficients for immigrants from Western Europe and OECD countries. Red bars denote the coefficients from rest of world countries. Statistically significance is denoted by a solid color. Statistically insignificant coefficients are denoted by bars containing lines.

\section{$<<$ Figure 6 about here $>>$}

Panel A shows that households are between $0.1 \%$ and $1.2 \%$ more likely to complain about heating, general levels of noise and pollution, vandalism, and financial problems following a one percentage point increase in immigrants from rest of world countries. They are also $1 \%$ more likely to have a bad perception about foreigners. ${ }^{36}$ In contrast, the same inflow of immigrants from Western Europe and OECD countries provokes no such complaints. In case of noise, vandalism, and the overall perception towards foreigners, these immigrants even slightly improve the situation of incumbent households. Similar results have been documented in social survey data and in the literature on racial preference and patterns of residential segregation (Bruch and Mare, 2006).

Panel B regresses the total number of complaints on immigration and the usual control variables. ${ }^{37}$ The first two columns show conventional OLS estimates. The last two columns show similar results based on a panel poisson regression which may be more affective at capturing the count data nature of the dependent variable. For instance, a one percentage point increase in net immigration from rest of world countries increases the number of problems reported by

\footnotetext{
${ }^{36}$ This variable was created from the following interview question: "Are you in favour of Switzerland offering foreigners the same opportunities as those offered to Swiss citizens, or in favour of Switzerland offering Swiss citizens better opportunities?". We assign a 1 to the variable "bad perception about foreigners" if a household answers with "in favour of better opportunities for Swiss citizens" and a 0 if they answer "in favour of equal opportunities".

${ }^{37}$ The control variables include house prices or rents, wages, average years of education, household age, number of children, and three binary variables indicating whether the household is a family household, has recently married, or recently had a new child.
} 
homeowners on average by $4.59 \%$. From the empirical results presented in Figure 6 and before we conclude that immigration flows can have economically large displacement effects and impacts the satisfaction levels of those households who remain. 


\section{Conclusion}

We analyze the displacement effects of households in response to large-scale immigration to Switzerland. We identify three channels that induce households to seek a new accommodation. First, immigration generates demand for housing space, thereby driving up prices and rents. Higher prices in turn can affect the location decisions of households, in particular for those with a preexisting pressure to relocate. Second, immigration increases the labor supply, which can lead to labor market competition and reduced wages. Lower wages may act as financial constraints and can affect the ability of households to move to a new area. Finally, a household may relocate due to sentiments, racial preference, and expectations about the effects of immigration. In this case, relocation could be driven by preferences regarding the composition of its neighborhood or by expectations about future labor and real estate market competition, even if these have not yet materialized.

We combine four large and detailed datasets to test all three channels. Switzerland has experienced large-scale immigration over the past few decades and is culturally and linguistically similar to its neighbors (Germany, France Austria and Italy). Our data therefore serves as an ideal setting to test the effects of immigration on an incumbent population, adding valuable insights to the discussion surrounding immigration in Europe. Our data contains the universe of immigrants to arrive in Switzerland between 1992 and 2013, granular house prices at the municipality level for both rented and owned properties, location data on swiss households as well as detailed socioeconomic and location data for over 7000 households over a period of 16 years.

Our empirical results reveal a high degree of heterogeneity in the impacts from immigration. Immigration from Western Europe and OECD countries have a larger effect on house prices than a comparable inflow of immigrants from rest of world countries. They also compete with different employment sectors and appear to be generally well received by the incumbent population. We find that one standard deviation changes in house prices, wages, and immigration have economically large effects on the relocation probability of incumbent households. However, we find that housing and labor markets, while relevant by themselves, are not important channels through which immigration causes household displacement. In fact, the main impact on displacement appears to come from immigration directly. Our findings suggest that households decide to move because of sentiment effects which include racial preference and expectations of future developments. 
Overall, our results provide valuable insights on the effects of immigration on an incumbent population. We can show that some households benefit from certain types of migration, while other households face increased competition. Our findings may be relevant for policy makers and can help to address the long-term implications of immigration on different sub-groups of the incumbent population. 


\section{References}

Akbari, A. H., and Y. Aydede (2012). "Effects of immigration on house prices in Canada", Applied Economics 44(13), 1645-1658.

Bartel, A.P. (1989). “Where do New U.S. Immigrants Live?”, Journal of Labor Economics 7(4), 371-391.

Basten, C., and C. Koch (2015). "The causal effect of house prices on mortgage demand and mortgage supply: Evidence from Switzerland", Journal of Housing Economics 30, 1-22.

Beerli, A., and G. Peri (2017). "The Labor Market Effects of Opening the Border: Evidence from Switzerland", Working paper available at https://www.research-collection.ethz.ch/bitstream/handle/ 20.500.11850/169157/wp_431.pdf? sequence=1\&isAllowed=y

Becker, G.S., and K.M. Murphy (2003). "Social Economics: Market Behavior in a Social Environment", Belknap Press.

Blickle, K., and M. Brown (2016). "Liquidity Constraints, Wealth Transfers and Home Ownership", St. Gallen Working paper. SSRN Electronic Journal. http://doi.org/10.2139/ssrn.2839217

Borjas, G.J. (2006). "Native Internal Migration and the Labor Market Impact of Immigration", Journal of Human Resources 41(2), 221-258.

Bruch, E., and R. Mare (2006). "Neighborhood Choice and Neighborhood Change", American Journal of Sociology 112(3), 667-709.

Card, D. (2001). "Immigrant Inflows, Native Outflows, and the Local Labor Market Impacts of Higher Immigration", Journal of Labor Economics 19(1), 22-64.

Card, D. (2007). "How Immigration Affects U.S. Cities", CReAM Discussion Paper No.11/07, available at http://www.cream-migration.org/publ_uploads/CDP_11_07.pdf

Card, D. (2009). "Immigration and Inequality”, American Economic Review 99(2), 1-21.

Cortes, P. (2008). "The Effect of Low-Skilled Immigration on U.S. Prices: Evidence from CPI Data", Journal of Political Economy 116(3), 381-422.

Degen, K., and A. M. Fischer (2017). "Immigration and Swiss House Prices", Swiss Journal of Economics and Statistics 153(1), 15-36.

Elhorst, P. (2014). "Spatial Econometrics: From Cross-Sectional Data to Spatial Panels", Springer.

Esses, V. M., U. Wagner, C. Wolf, M. Preiser, and C. J. Wilbur (2006). "Perceptions of national identity and attitudes toward immigrants and immigration in Canada and Germany". International Journal of Intercultural Relations 30(6), 653-669.

Fahrländer, S. (2006). "Semiparametric Construction of Spatial Generalized Hedonic Models for Private Properties", Swiss Journal of Economics and Statistics 142(4), 501-528.

Fahrländer, S. (2008). "Indirect Construction of Hedonic Price Indexes for Private Properties", Swiss Journal of Economics and Statistics 144(4), 607-630.

Filer, R. (1992). "The Effect of Immigrant Arrivals on Migratory Patterns of Native Workers. Immigration and the Workforce: Economic Consequences for the United States and Source Areas", in Borjas, G. and R. Freeman (eds.), NBER book, 245-270.

Firpo, S., N.M. Fortin, and T. Lemieux (2009). "Unconditional Quantile Regressions”, Econometrica 77(3), 953-973.

Fitzgerald, J. (1999). “Money Growth and Inflation: How Long is the Long-Run?”, Economic Commentary Federal Reserve Bank of Cleveland. 
Fitzgerald, J., K. A. Curtis, and C. L. Corliss (2012). "Anxious Publics: Worries about Crime and Immigration", Comparative Political Studies 45(4), 477-506.

Frey, W. H. (1995). "Immigration and Internal Migration "Flight": A California Case Study", Population and Environment 16(4) 353-375.

Gonzalez, L., and F. Ortega (2013). "Immigration and Housing Booms: Evidence from Spain", Journal of Regional Science 53(1), 37-59.

Guerrieri, V., D. Hartley, and E. Hurst (2013). "Endogenous Gentrification and Housing Price Dynamics", Journal of Public Economics, 100, 45-60.

Ha, S. E., and S. J. Jang (2014). "Immigration, Threat Perception, and National Identity: Evidence from South Korea", International Journal of Intercultural Relations 44, 53-62.

Halla, M., A. Wagner and J. Zweimüller (2017). "Immigration and Voting for the Far Right", Journal of the European Economic Association 15(6), 1341-1385.

Hatton, T.J., and M. Tani (2005). "Immigration and Inter-Regional Mobility in the UK, 1982-2000", The Economic Journal 115(507), 342-358.

Helms, A. C. (2003). "Understanding Gentrification: An Empirical Analysis of the Determinants of Urban Housing Renovation", Journal of Urban Economics 54(3), 474-498.

Kritz, M., and D. T. Gurak (2001). "The Impact of Immigration on the Internal Migration of Natives and Immigrants", Demography 38(1), 133-145.

LeSage, J., and Y.-Y. Chih (2016). "Interpreting Heterogeneous Coefficient Spatial Autoregressive Panel Models", Economics Letters 142, 1-5.

LeSage, J., and K. Pace (2009). "Introduction to Spatial Econometrics", London: CRC Press.

Lester, T. W., and D. A. Hartley (2014). "The Long-Term Employment Impacts of Gentrification in the 1990s", Regional Science and Urban Economics 45, 80-89.

Ley, D., J. Tutchener, and G. Cunningham (2002). "Immigration, Polarization, or Gentrification? Accounting for Changing House Prices and Dwelling Values in Gateway Cities", Urban Geography 23(8), 703-727.

Logan, J.R., and C. Zhang (2010). "Global Neighborhoods: New Pathways to Diversity and Separation", Journal of Sociology 115(4), 1069-1109.

Maddens, B., J. Billiet, and R. Beerten (2000). "National Identity and the Attitude Towards Foreigners in Multi-National States: The Case of Belgium", Journal of Ethnic and Migration Studies, 26(1), 4560.

Massey, D., R. Alarcón, J. Durand, and H. Gonzalez (1987). "Return to Aztlan: The Social Process of International Migration from Western Mexico", Berkley: University of California.

McKinnish, T., R. Walsh, and K. White (2010). “Who Gentrifies Low-Income Neighborhoods?” Journal of Urban Economics 67(2), 180-193.

Meen, G. (2010). "Regional House Prices and the Ripple Effect: A New Interpretation", Housing Studies 14(6), 733-753.

Munshi, K. (2003). "Networks in the Modern Economy: Mexican Migrants in the US Labor Market", Quarterly Journal of Economics, 118(2), 549-599.

Orrenius, P.M., and M. Zavodny (2007). "Does Immigration Affect Wages? A Look at Occupation-Level Evidence", Labour Economics 14, 757-773.

O'Sullivan, A. (2005). "Gentrification and Crime”, Journal of Urban Economics 57(1), 73-85. 
Ottaviano, G., and G. Peri (2011). "Rethinking the Effect of Immigration on Wages", Journal of the European Economic Association 10(1), 152-197.

Peri, G., and C. Sparber (2009). "Task Specialization, Immigration, and Wages", American Economic Journal: Applied Economics 1(3), 135-169.

Peri, G., and C. Sparber (2011). "Assessing Inherent Model Bias: An Application to Native Displacement in Response to Immigration”, Journal of Urban Economics 69(1), 82-91.

Pissarides, C.A., and G. Weber (1989). "An Expenditure-Based Estimate of Britain's Black Economy", Journal of Public Economics 39, 17-32.

Rath, J., and R. Kloosterman (2000). “Outsiders' Business: A Critical Review of Research on Immigrant Entrepreneurship”, International Migration Review 34(3), 657-681.

Sá, F. (2014). "Immigration and House Prices in the UK", The Economic Journal 125(587), 1393-1424.

Saiz, A. (2007). "Immigration and Housing Rents in American Cities", Journal of Urban Economics 61(2), $345-371$.

Saiz, A. (2010). "The Geographic Determinants of Housing Supply", Quarterly Journal of Economics 125(3), 1253-1296.

Sieg, H., V.K. Smith, H.S. Banzhaf, and R. Walsh (2004). "Estimating the General Equilibrium Benefits of Large Changes in Spatially Delineated Public Goods", International Economic Review 45(4): 104777.

Thornton, D.L. (2011). “The FOMC's Interest Rate Policy: How Long is the Long Run?”. Economic Synopses Federal Reserve Bank of St.Louis, No.29.

Wang, X. (2012). "Undocumented Immigrants as Perceived Criminal Threat: A Test of the Minority Threat Perspective", Criminology 50(3), 743-776.

Wright, M. (2011). "Diversity and the Imagined Community: Immigrant Diversity and Conceptions of National Identity", Political Psychology 32(5), 837-862.

Zelekha, Y. (2013). "The Effect of Immigration on Entrepreneurship”, Kyklos 66(3), 438-465. 
Figure 1: Economic Channels of Immigration

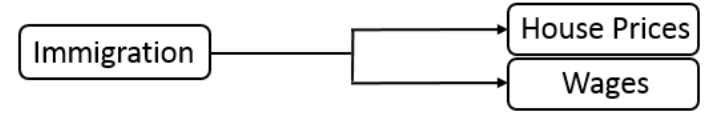

Model I

Immigration $\longrightarrow$ Hages $\longrightarrow \begin{gathered}\text { Propensity to } \\ \text { Move }\end{gathered}$

Model II

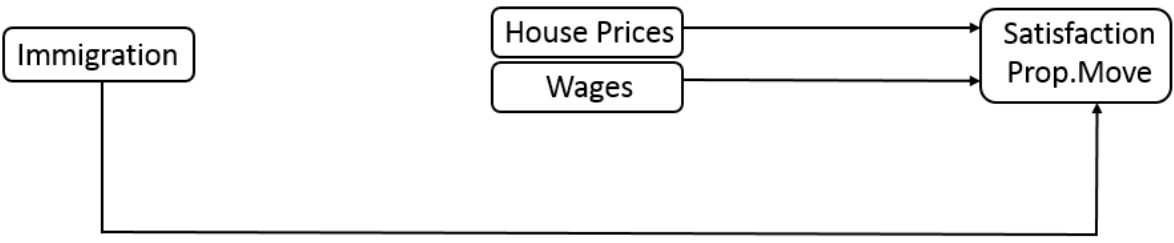

Model III

This figure shows the three causality channels that we aim to investigate in this paper. In model I we estimate the exogenous impact of immigration on house prices and labor income. In model II, we are interested in the indirect effect of immigration on households' propensity to relocate. House prices and wages thereby serve as transmission channels through which immigration causes displacement. Finally, in model III we explore the remaining direct effect of immigration, once house prices and wages are accounted for. We interpret this remaining effect from immigration as a sentiment or expectations channel. 
Figure 2: Net Immigration Flows (1992 - 2013)

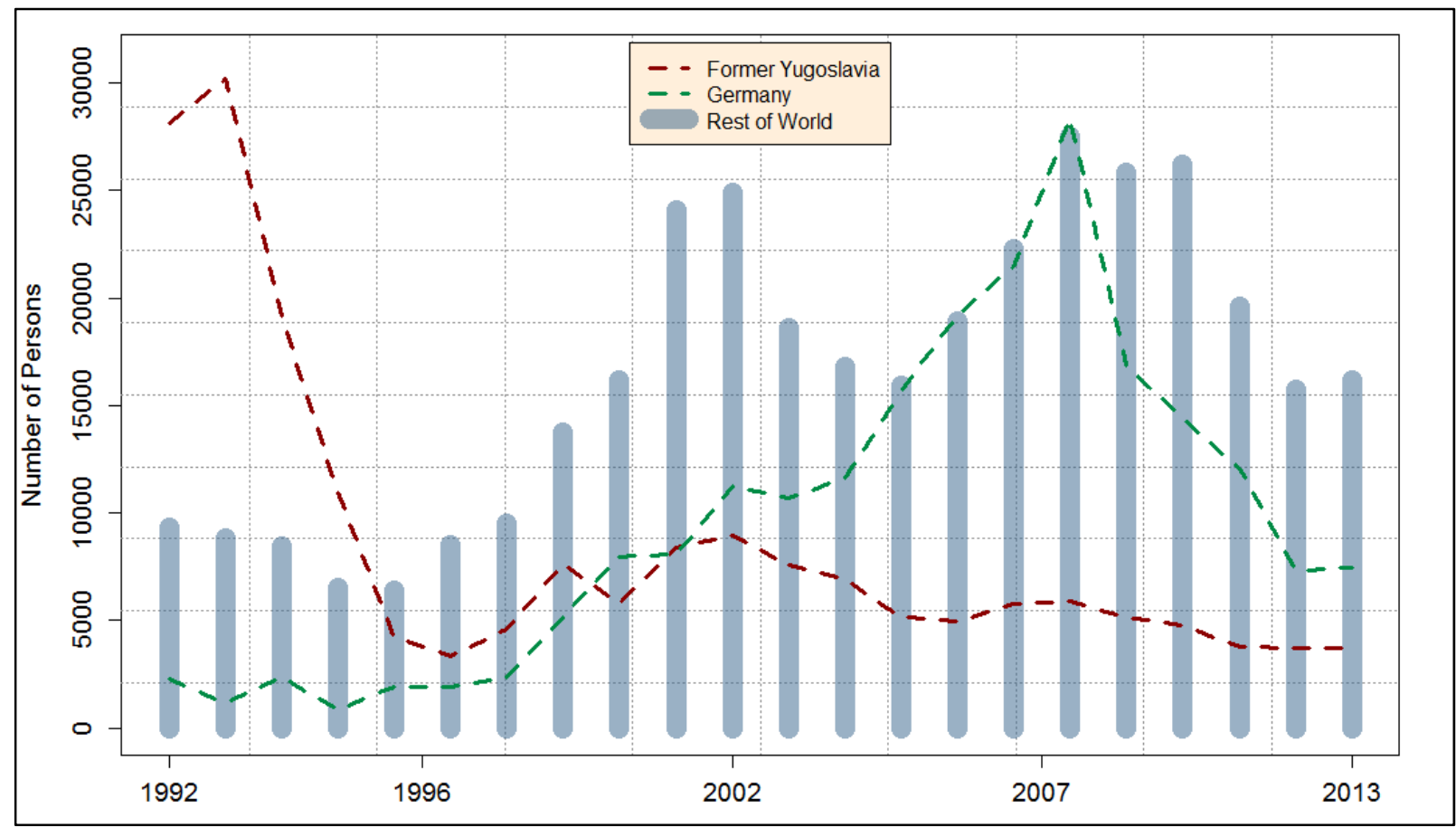

This figure shows the net immigration flows into Switzerland for selected countries. Immigrants from former Yugoslavia were the dominant group at the beginning of our sample in the early 1990s. Over time, immigrants from Germany became the main contributor to total immigration. Taken together, immigration flows from these two countries are comparable in size to the net immigration form all remaining non-OECD countries. 
Figure 3: Immigration Statistics and Spatial Clustering

\begin{tabular}{lcccc}
\hline Panel A: Immigration by Country of Origin (in '000 persons) \\
\hline & Immigration & Emigration & $\begin{array}{c}\text { Net } \\
\text { Immigration }\end{array}$ & $\begin{array}{c}\text { \% of Swiss } \\
\text { Population }\end{array}$ \\
\cline { 2 - 5 } Austria & 178 & 166 & 12 & 0.2 \\
Former Yugo. & 772 & 583 & 189 & 3.1 \\
France & 405 & 342 & 63 & 1 \\
Germany & 1052 & 841 & 211 & 3.4 \\
Italy & 658 & 672 & -14 & -0.2 \\
Portugal & 877 & 801 & 76 & 1.2 \\
Spain & 197 & 238 & -41 & -0.7 \\
Turkey & 163 & 139 & 24 & 0.4 \\
United Kingdom & 169 & 145 & 24 & 0.4 \\
United States & 117 & 104 & 13 & 0.2 \\
Rest of World & 1,809 & 1,449 & 360 & 5.9 \\
\hline Total & 6,397 & 5,480 & 917 & 14.9 \\
\hline
\end{tabular}

Panel B: Average Net Immigration by Municipality (1992-2013)

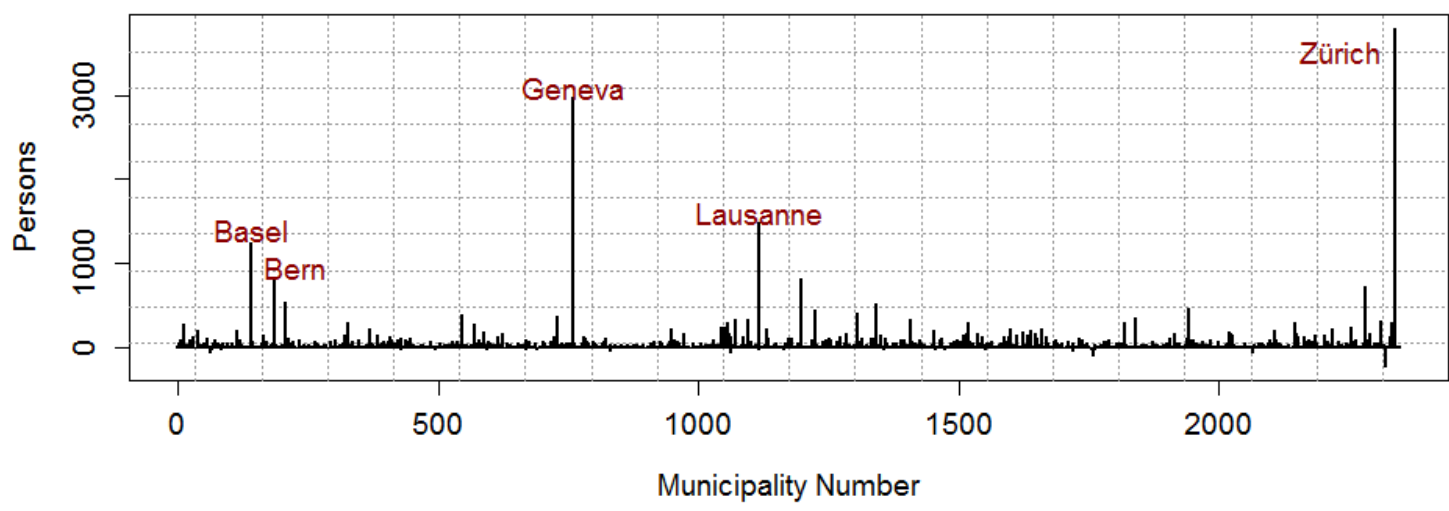

Panel C: Total Immigration by Municipality and Year in \% of Swiss Population

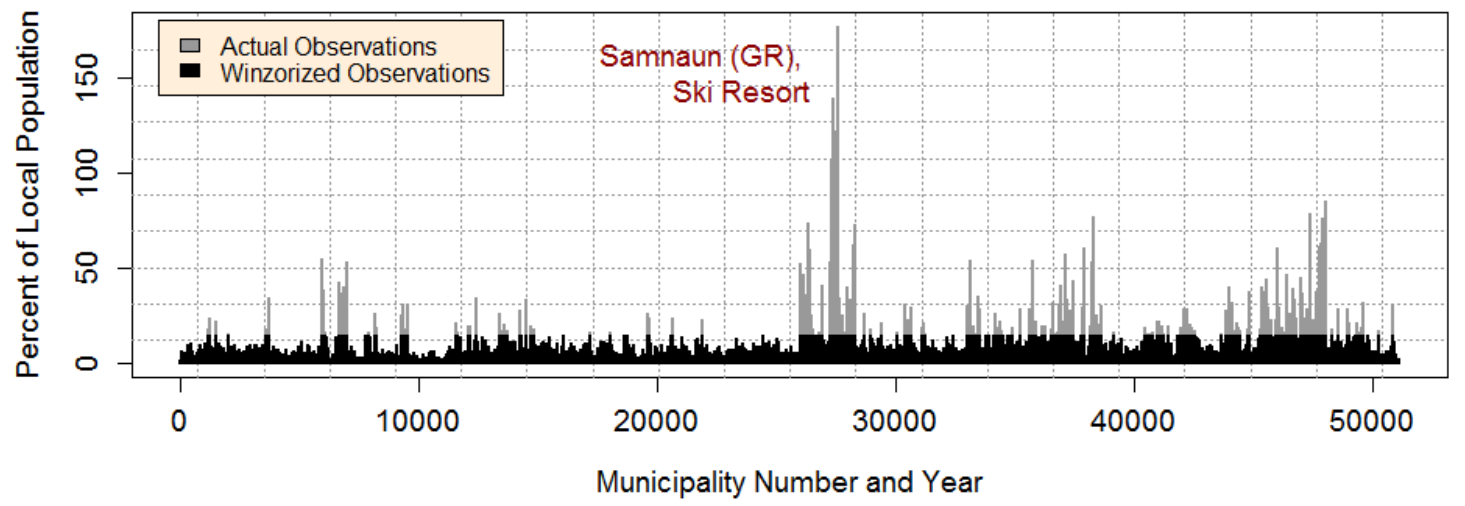

This figure shows immigration flows to Switzerland from 1992-2013. Panel A shows immigration numbers by country 
of origin. Immigration is measured in thousand persons. The last column of Panel A relates net immigration numbers to the average native Swiss population over this period. For instance, total net immigration from 1992-2013 amounts to $14.9 \%$ of the Swiss population. Panel B shows that a number of metropolitan regions receive the majority of immigration flows. In order to prevent the metropolitan regions to drive our results, we measure immigration as a percentage of the Swiss population in that municipality. Panel C shows the distribution of immigration measured in this way. We winsorize the observations at a cap of $15 \%$ to prevent the generation of outliers in popular tourist regions. Winzorization affects only $3.5 \%$ of our observations and the empirical results in this paper also hold with untreated variables. 


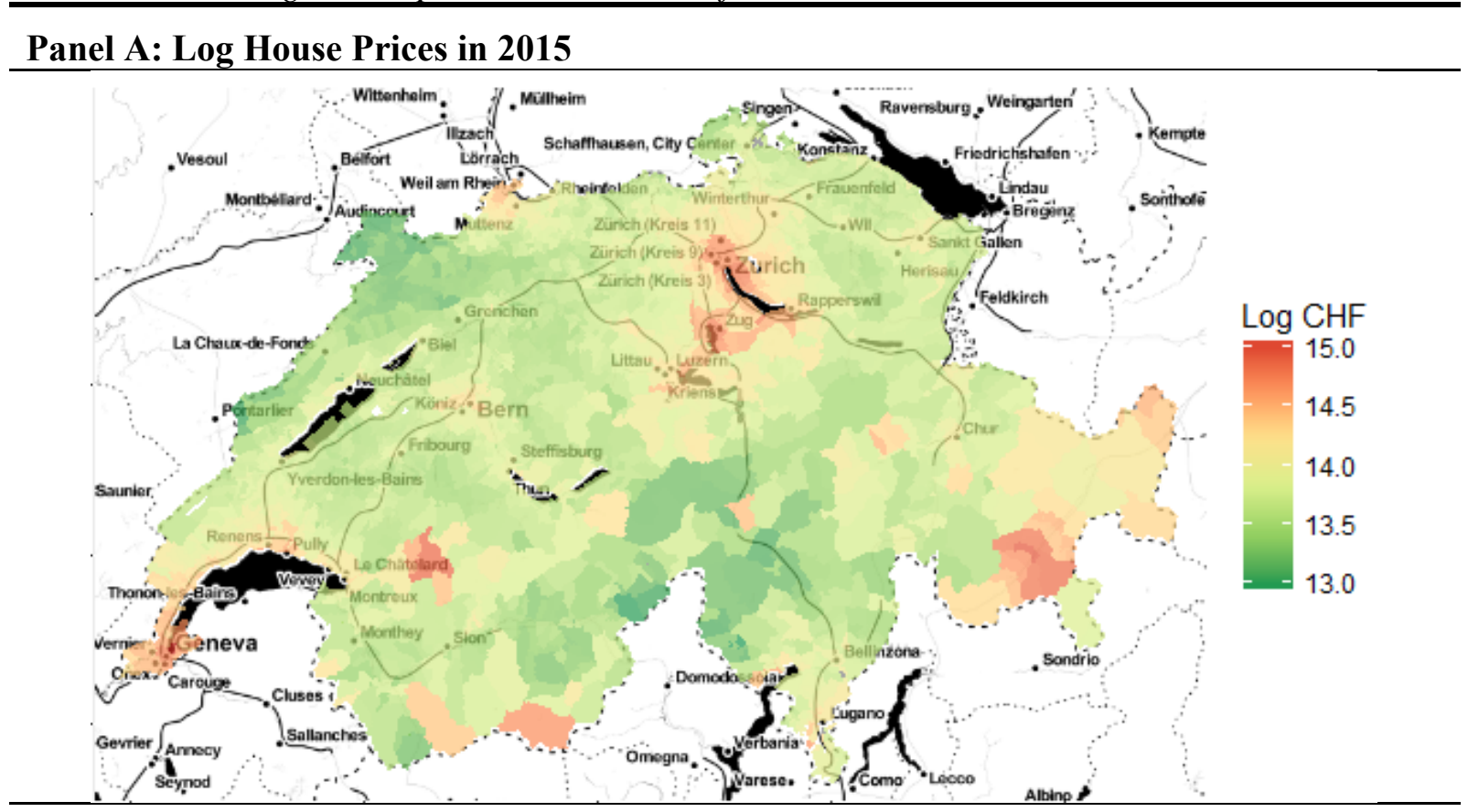

Panel B: House Price Growth Rates (1992-2015)

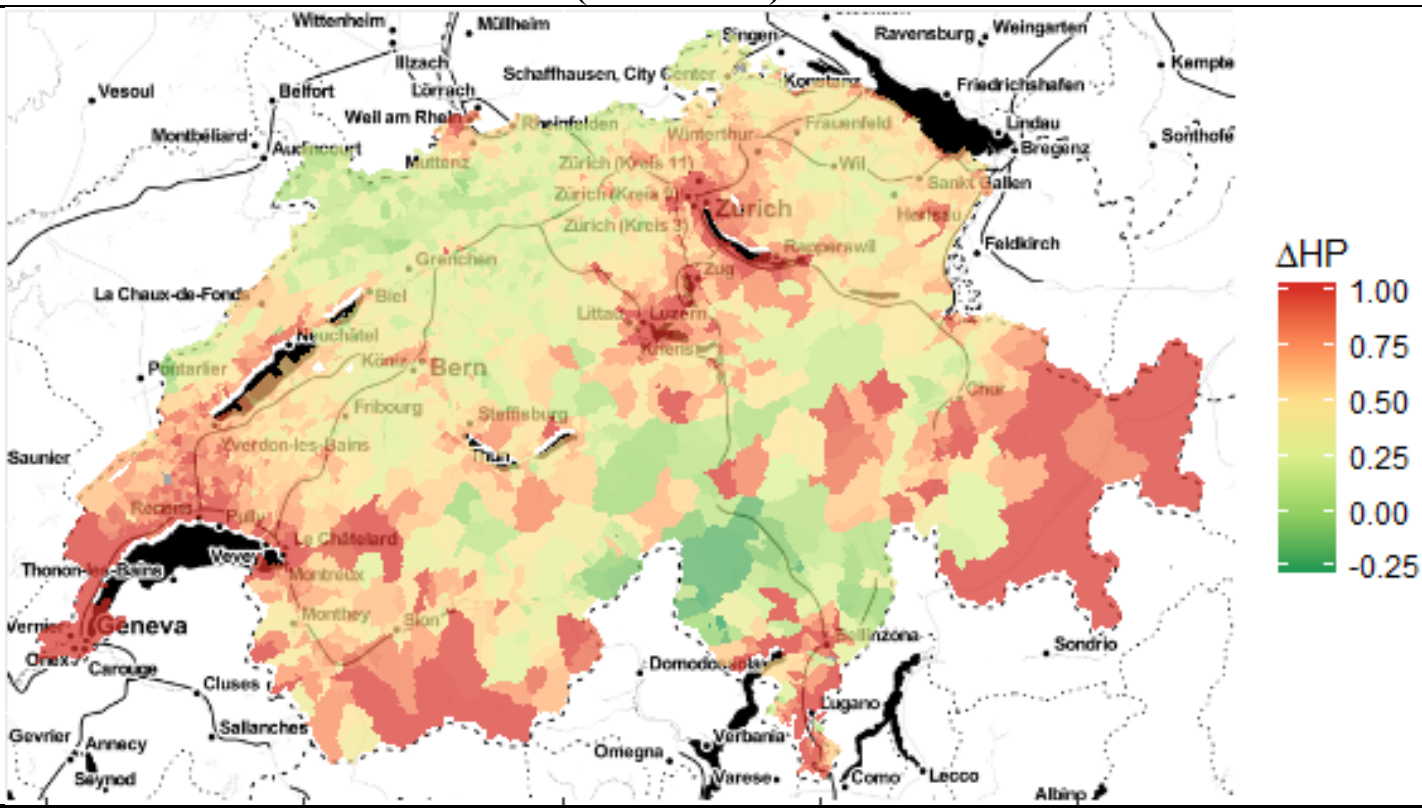

This figure plots house prices in log Swiss Francs for the 2,323 municipalities in Switzerland. High price metropolitan regions are Geneva in the west with average log house prices of 14.74 (about EUR 2.3 million), Basel in the northern part of the country with average log house prices of 14.47 (EUR 1.7 million) and the Zurich metropolitan area at the center of Switzerland with average house prices of 14.66 (EUR 2.15 million). The lowest house price region in 2015 was the municipality of Gresso in the canton of Ticino in the southern part of Switzerland with average $\log$ CHF house prices of 12.98 (EUR 400,000). Panel B shows the growth rates over the period 1992 2015. House prices located in red areas increased by $100 \%$ and more. 
Figure 5: Summary of Estimated Transmission Channels:

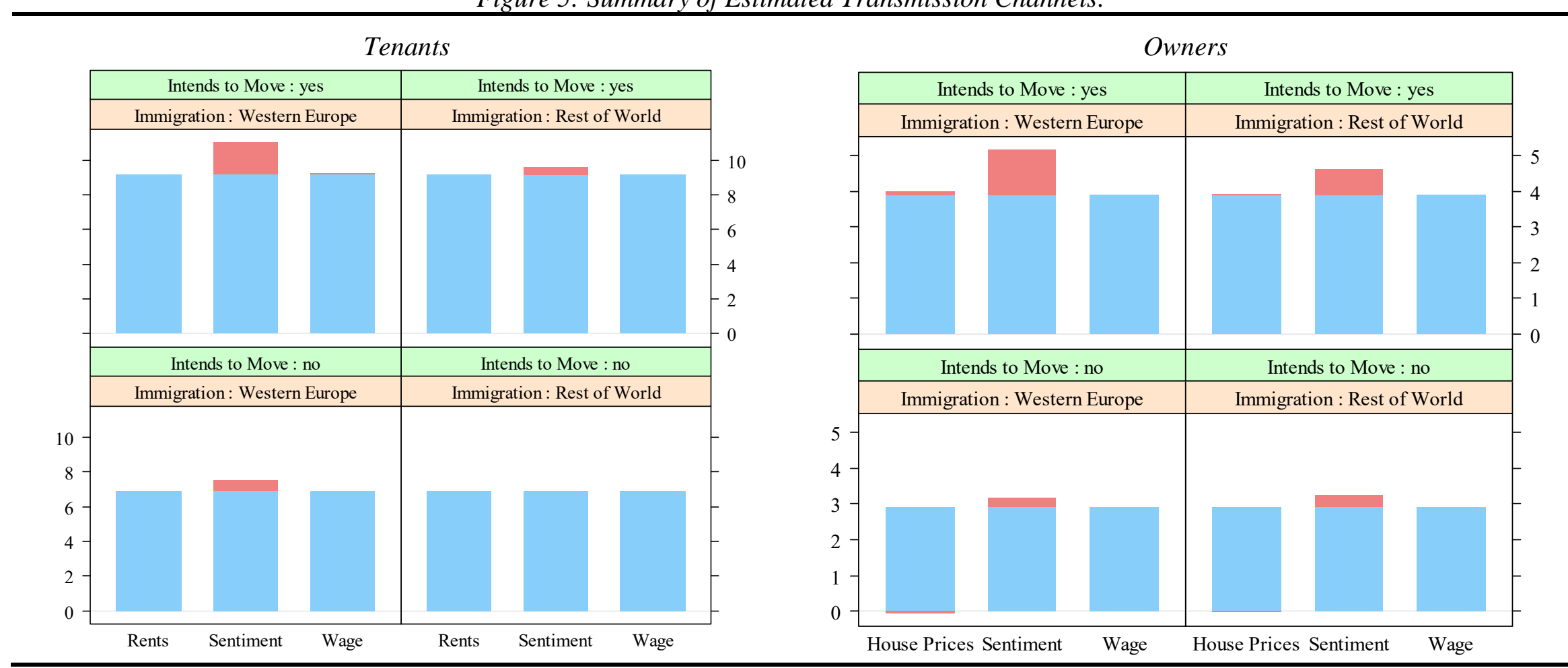

This figure shows a graphical summary of the marginal effects from a one standard deviation increase in immigration. The blue bar shows the percentage point unconditional propensity to move to a new municipality, which is $6.9 \%$ for tenants and $2.9 \%$ for owners. For households who have indicated that they intend to move this probability is somewhat higher $(9.2 \%$ for tenants and $3.9 \%$ for owners). The red bars show the increase in the propensity to move where we distinguish between housing market effects (rent and prices), wages, and the remaining residual or sentiment effect. If the marginal impact on the propensity to move is negative, the red area is added at the bottom of the blue bar. The marginal effects from changes in house prices, rents, and wages are based on the long-run total impacts of the SAR estimates. This has the advantage that the total impacts measure the effect over all regions instead of the shock-originating region only. The results show that (i) households with a preexisting intention to move respond more strongly to immigration and (ii) the main way through which immigration affects native households moving decisions is not through the house price or the wage channel but through immigration directly. 
Figure 6: Immigration and Satisfaction

\section{Panel A: Immigration and Household Complaints}

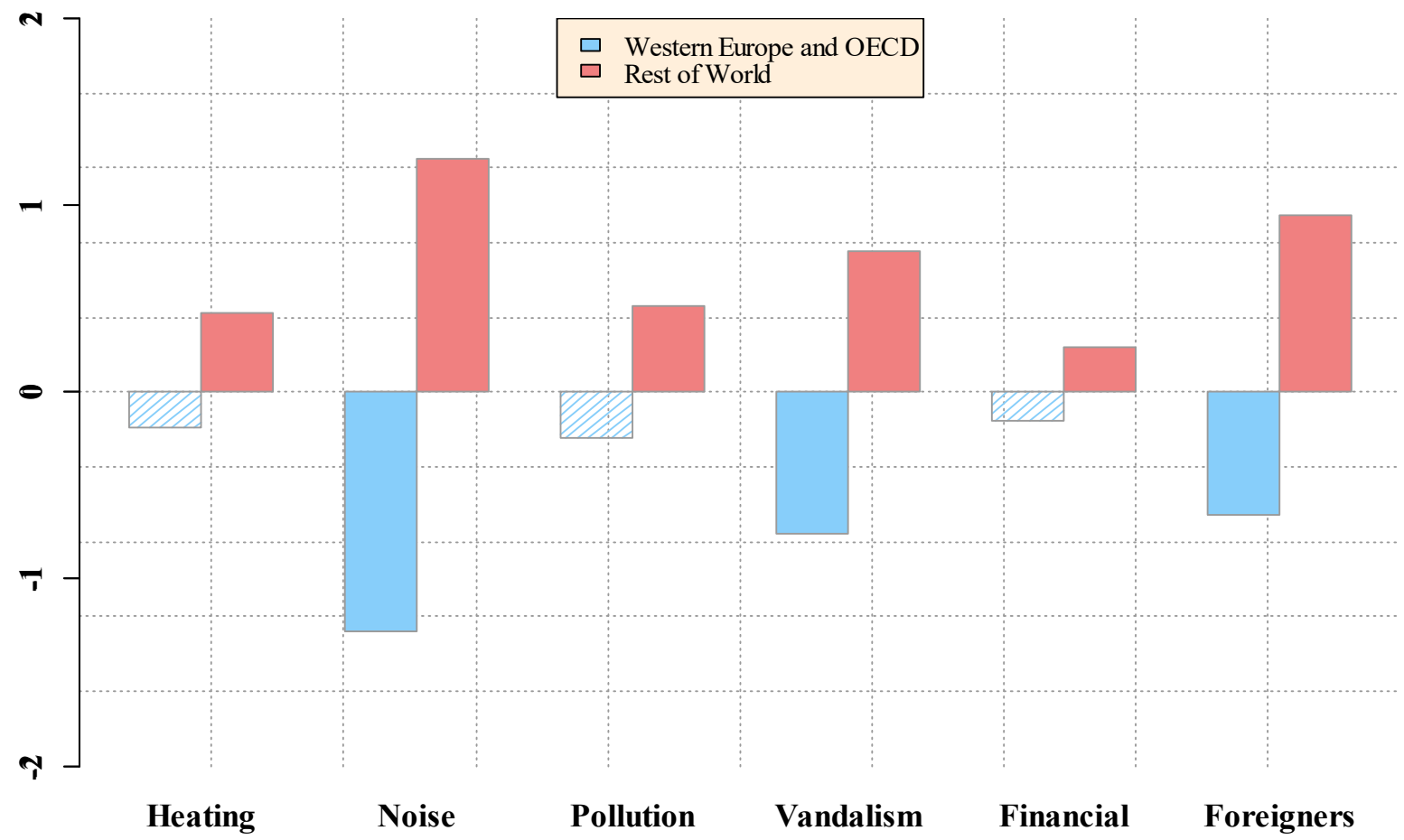

Panel B: Immigration and Satisfaction

Tenants

$-0.25$

2.21*

YES

YES

20,324

Panel OLS
Owners

$-1.24$

$2.19^{*}$

YES

YES

17,235

Panel OLS
Tenants

$-0.11$

3.98*

YES

YES

20,324

Methodology

This figure shows the estimated change in the satisfaction level of Swiss households following an increase in immigration over the last three years. Satisfaction is measured by six complaint items that are collected every year as part of the Swiss Household Panel. Panel A shows the estimated increase in probability that an incumbent household reports dissatisfaction with his accommodation concerning heating, noise, pollution, or vandalism, reports financial problems, or indicates a bad perception of foreigners. In Panel B, the sum of these six complaints are aggregated to one dissatisfaction variable and regressed on immigration over the last three years. For instance, a one percentage point increase in net immigration from Rest of World countries increases the expected number of reported problems by $4.59 \%$. The number of reported zeros in the data is less than $50 \%$. A zero-inflated Poisson regression is therefore not necessary here. One asterisk $\left(^{*}\right)$ denotes statistical significance at $10 \%$ or higher. 
Table 1: Propensity to Move Following an Increase in House Prices or Rents

\begin{tabular}{|c|c|c|}
\hline & $\begin{array}{c}\text { Tenants: } \\
\text { Rent Increase }\end{array}$ & $\begin{array}{c}\text { Owners: } \\
\text { House Price Increase } \\
\end{array}$ \\
\hline $\begin{array}{l}\text { Household Intends } \\
\text { to Move }\end{array}$ & $\begin{array}{l}\text { Higher rents increase propensity } \\
\text { to move }\end{array}$ & $\begin{array}{l}\text { Higher prices increase propensity } \\
\text { to move }\end{array}$ \\
\hline $\begin{array}{l}\text { Household Does } \\
\text { Not Intend to Move }\end{array}$ & $\begin{array}{l}\text { Higher rents decrease propensity } \\
\text { to move }\end{array}$ & $\begin{array}{l}\text { Higher prices have no effect on the } \\
\text { propensity to move }\end{array}$ \\
\hline \multicolumn{3}{|c|}{$\begin{array}{l}\text { his figure summarizes our hypothesis concerning households' propensity to move. Tenants respond to rent changes } \\
\text { vhile owners react to house prices. The sensitivity of these changes depends to a large extent on whether the household } \\
\text { ntends to move and therefore cares about current market rents and prices. For instance, tenants will be more likely to } \\
\text { espond to rising rents if family or job related factors are already generating relocation pressure. In contrast, tenants } \\
\text { vho do not intend to move respond negatively to higher rents because they benefit from the lower rent on existing } \\
\text { ontracts. Relocation would mean having to rent at the higher current market rate. }\end{array}$} \\
\hline
\end{tabular}


Table 2: Summary Statistics for Individual Households

\begin{tabular}{|c|c|c|c|}
\hline \multicolumn{4}{|l|}{ Panel A: Propensity to Move } \\
\hline & $\begin{array}{l}\text { Area with high } \\
\text { immigration }\end{array}$ & $\begin{array}{l}\text { Area with low } \\
\text { immigration }\end{array}$ & Difference \\
\hline Household moves & $27 \%$ & $28 \%$ & $1 \%{ }^{*}$ \\
\hline Household moves to a cheaper area & $16 \%$ & $14 \%$ & $2 \%{ }^{* * *}$ \\
\hline Household ever owns a home & $35 \%$ & $42 \%$ & $7 \%{ }^{* * *}$ \\
\hline \multicolumn{4}{|c|}{ Panel B: Socioeconomic Characteristics of Households } \\
\hline & Household moves & Household does not move & Difference \\
\hline Age of primary respondent & 45.4 & 55.2 & $-9.8^{* * *}$ \\
\hline Years of education (H.H. average) & 13.5 & 12.5 & $1.0^{* * *}$ \\
\hline Married or living together & 0.6 & 0.6 & $0.0^{* * *}$ \\
\hline Average income* (in 100,000 CHF) & 1 & 0.9 & $0.1^{* * *}$ \\
\hline Number of Children & 0.6 & 0.5 & $0.1^{* * * *}$ \\
\hline Household is of Swiss Origin $* *(y=1)$ & 0.6 & 0.7 & $-0.1^{* * *}$ \\
\hline Household Political Stance $(10=$ right $)$ & 4.6 & 4.9 & $-0.2^{* * *}$ \\
\hline
\end{tabular}

This figure shows descriptive statistics for household behavior and socioeconomic background. Panel A shows household's propensity to move for high and low immigration scenarios. A municipality is identified as a high immigration region if exogenous net immigration exceeds median immigration in Switzerland. Panel B compares socioeconomic characteristics of households that move with households that remain. 
Table 3: Estimating Equations

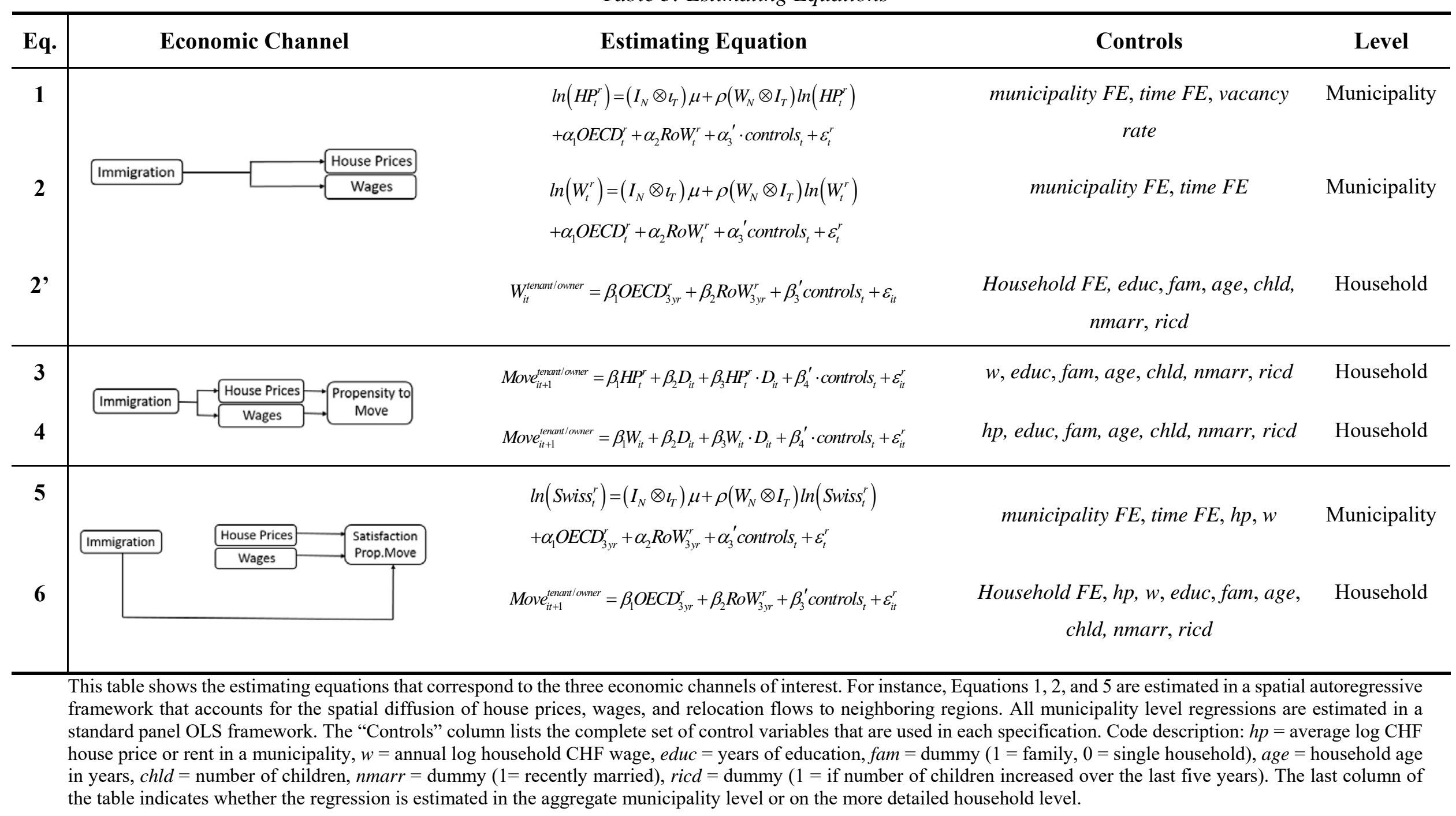


Table 4: Immigration and House Prices

Short Run Long Run 1 Or.Neigh. 2 Or.Neigh.

Panel A: OLS Estimates

\begin{tabular}{|c|c|c|c|c|}
\hline Net Immigration West and OECD & $2.87^{*}$ & - & - & - \\
\hline Net Immigration RoW & $1.01 *$ & - & - & - \\
\hline Vacancy Rate & $-0.29^{*}$ & - & - & - \\
\hline Municipality Fixed Effects & YES & - & - & - \\
\hline Year Fixed Effects & YES & - & - & - \\
\hline Observations & 51,106 & - & - & - \\
\hline Adj.R-Squared & 0.89 & - & - & - \\
\hline
\end{tabular}

Panel B: SAR Estimates

Net Immigration West and OECD

$1.15^{*}$

1.43

0.39

0.18

Net Immigration RoW

$0.37^{*}$

0.46

0.13

0.06

Vacancy Rate

$-0.06^{*}$

Spatial Lag

$0.82^{*}$

Municipality Fixed Effects

YES

Year Fixed Effects

YES

Observations

51,106

Adj.R-Squared

0.96

This table shows the impact and spatial diffusion of immigration on house prices.

The estimating equation is $\ln \left(H P_{t}^{r}\right)=\left(I_{N} \otimes l_{T}\right) \mu+\rho\left(W_{N} \otimes I_{T}\right) \ln \left(H P_{t}^{r}\right)+\alpha_{1} O E C D_{t}^{r}+\alpha_{2} \operatorname{RoW}_{t}^{r}+\alpha_{3}^{\prime} \cdot$ controls $_{t}+\varepsilon_{t}^{r}$. Panel A shows the conventional OLS estimates. A typical finding is that the OLS parameters are higher in absolute terms than their spatial autoregressive (SAR) counterparts in Panel B. This is because OLS predicts the entire response to occur in the immigration region while SAR allows for the response to be partly transmitted to neighboring regions. "Short Run" denotes the short-run response of house prices to an increase in immigration. "Long Run" denotes the long-run response of house prices in the same region. 1 Or.Neigh. denotes the long-run response of house prices in the first order neighbors of the region that experiences an immigration inflow. First order neighbors are the six closest municipalities to the immigration municipality. 2 Or.Neigh. denotes the house prices response in second order neighbors which are the neighboring municipalities to the first order neighbors. Immigration denotes exogenous net immigration, as a share of the local population. The adjusted R-squared values include the explanatory power from municipality and time fixed-effects and are much lower when estimated on demeaned data. One asterisk $\left(^{*}\right)$ denotes statistical significance at $10 \%$ or higher. 
Table 5: Immigration and Wages (Aggregate Level Effects)

\section{Short Run Long Run 1 Or.Neigh. 2 Or.Neigh.}

Panel A: OLS Estimates

\begin{tabular}{|c|c|c|c|c|}
\hline Net Immigration West and OECD & $1.09^{*}$ & - & - & - \\
\hline Net Immigration RoW & $-0.57^{*}$ & - & - & - \\
\hline Municipality Fixed Effects & YES & - & - & - \\
\hline Year Fixed Effects & YES & - & - & - \\
\hline Observations & 27,876 & - & - & - \\
\hline Adj.R-Squared & 0.91 & - & - & - \\
\hline
\end{tabular}

Panel B: SAR Estimates

Net Immigration West and OECD

0.79

0.91

0.18

0.08

Net Immigration RoW

$-\mathbf{0 . 3 8}$

$-0.44$

$-0.09$

$-0.04$

Spatial Lag

$0.45^{*}$

Municipality Fixed Effects

YES

Year Fixed Effects

YES

Observations

27,876

Adj.R-Squared

0.91

This table shows the impact and spatial diffusion of immigration on wages.

The estimating equation is $\ln \left(W_{t}^{r}\right)=\left(I_{N} \otimes l_{T}\right) \mu+\rho\left(W_{N} \otimes I_{T}\right) \ln \left(W_{t}^{r}\right)+\alpha_{1} O E C D_{t}^{r}+\alpha_{2} R_{0} W_{t}^{r}+\alpha_{3}^{\prime}$ controls $_{t}+\varepsilon_{t}^{r}$. Panel A shows the conventional OLS estimates. A typical finding is that the OLS parameters are higher in absolute terms than their spatial autoregressive (SAR) counterparts in Panel B. This is because OLS predicts the entire response to occur in the immigration region while SAR allows for the response to be partly transmitted to neighboring regions. "Short Run" denotes the short-run response of wages to an increase in immigration. "Long Run" denotes the long-run response of wages in the same region. 1 Or.Neigh. denotes the long-run response of wages in the first order neighbors of the region that experiences an immigration inflow. First order neighbors are the six closest municipalities to the immigration municipality. 2 Or.Neigh. denotes the wage response in second order neighbors which are the neighboring municipalities to the first order neighbors. Immigration denotes exogenous net immigration, as a share of the local population. The sample period is from 2002 to 2013 (annual data). The adjusted R-squared values include the explanatory power from municipality and time fixed-effects and are much lower when estimated on demeaned data. One asterisk $\left(^{*}\right)$ denotes statistical significance at $10 \%$ or higher. 
Table 6: Immigration and Wages (Individual Household Level Effects)

\section{Panel A: Individual Household Level OLS Estimates}

\begin{tabular}{lcc} 
& Tenants & Owners \\
\cline { 2 - 3 } Net Immigration West and OECD & 0.83 & $\mathbf{- 1 . 6 7 ^ { * }}$ \\
Net Immigration RoW & $\mathbf{- 0 . 9 5}^{*}$ & 0.57 \\
Household Fixed Effects & Yes & Yes \\
Time-Varying Household Controls & Yes & Yes \\
Observations & 24,348 & 23,419 \\
Adj.R-Squared & 0.77 & 0.76
\end{tabular}

\section{Panel B: Individual Household Level Quantile Regression Effects}

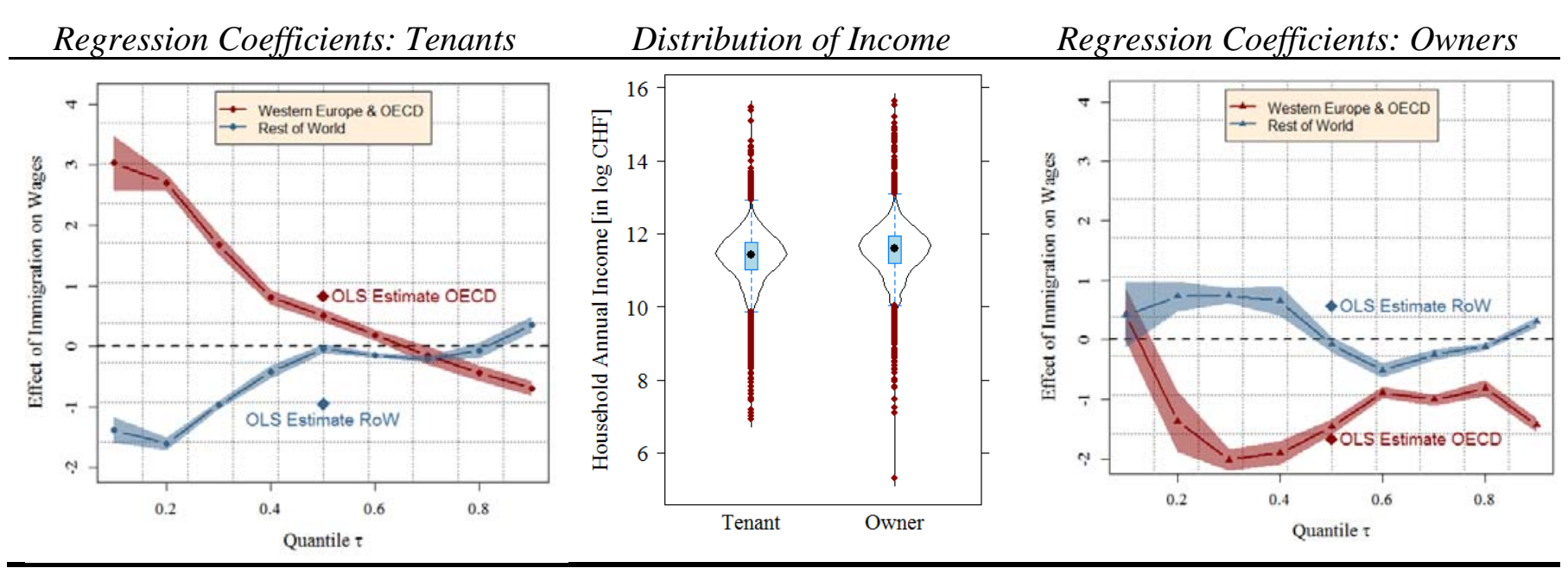

This table shows the impact of immigration on household level wages.

The estimating equation is $W_{i t}^{\text {tenant/owner }}=\beta_{1} O E C D_{3 y r}^{r}+\beta_{2}$ RoW $_{3 y r}^{r}+\beta_{3}^{\prime}$ controls ${ }_{t}+\varepsilon_{i t}$. Panel A shows that the wages of tenants and owners respond differently to immigration. The results appear to be partly inconsistent with our findings on the aggregate level (see Table 5). To resolve this issue, Panel B shows the wage response in a panel quantile regression framework. The estimates are based on the unconditional quantile regression methodology of Firpo, Fortin, and Lemieux (2009). The results in Panel B show that the wages of low income tenants respond positively to high skilled immigration but decrease following an inflow of low skilled immigrants. These results are in line with findings from previous studies on complementarity and substitution effects in labor markets. One asterisk $\left({ }^{*}\right)$ denotes statistical significance at $10 \%$ or higher. 
Table 7: The House Price Channel of Displacement

Panel A: One Percent Increase in Rents and House Prices

\begin{tabular}{lcccc}
\hline & \multicolumn{2}{c}{ Tenants } & \multicolumn{2}{c}{ Owners } \\
\cline { 2 - 5 } Log(Rents) or Log(Prices) & $\mathbf{- 0 . 0 5 4 ^ { * }}$ & $\mathbf{- 0 . 0 5 9 ^ { * }}$ & $\mathbf{- 0 . 0 1 8}^{*}$ & $\mathbf{- 0 . 0 2 1}^{*}$ \\
Interaction: HH. Intends to move & - & $\mathbf{0 . 0 5 0 ^ { * }}$ & - & $\mathbf{0 . 0 4 7}^{*}$ \\
\cline { 2 - 5 } Household Fixed Effects & YES & YES & YES & YES \\
Time-Varying Household Controls & YES & YES & YES & YES \\
Observations & 24,237 & 20,347 & 20,083 & 17,285 \\
Adj.R-Squared & 0.33 & 0.40 & 0.21 & 0.34 \\
\hline
\end{tabular}

Panel B: One Standard Deviation Increase in Rents (CHF 2,249) and House Prices (CHF 172,306)

Tenants

Owners

$\begin{array}{lcccc}\log (\text { Rents) or } \log (\text { Prices }) & -0.53 & -0.53 & -0.13 & -0.14 \\ \text { Interaction: HH. Intends to move } & - & 0.42 & - & 0.47\end{array}$

Panel C: Indirect Effect of One Standard Deviation Increase in Immigration (0.59 pct. points)

\begin{tabular}{lcccc}
\hline & \multicolumn{2}{c}{ Tenants } & \multicolumn{2}{c}{ Owners } \\
\cline { 2 - 5 } $\log ($ Rents) or Log(Prices) & $-\mathbf{0 . 0 3 7}$ & $\mathbf{- 0 . 0 4 0}$ & $\mathbf{- 0 . 0 1 2}$ & $\mathbf{- 0 . 0 1 4}$ \\
Interaction: HH. Intends to move & - & 0.034 & - & $\mathbf{0 . 0 3 1}$
\end{tabular}

This table shows the effect of an increase in rents and house prices on the propensity that a household relocates to a new municipality.

The estimating equation is Move $_{i t+1}^{\text {tenant/owner }}=\beta_{1} H P_{t}^{r}+\beta_{2} D_{i t}+\beta_{3} H P_{t}^{r} \cdot D_{i t}+\beta_{4}^{\prime} \cdot$ controls $_{t}+\varepsilon_{i t}^{r}$. Panel A shows the regression coefficients for a one percent increase. We use rents if the households is a tenant and the average single family house price for that municipality in case the household is an owner. We run individual regressions for tenants and owners to accommodate the fact that both groups respond differently to house price or rent shocks. We include an interaction term "household intends to move" to incorporate the particular effects of the Swiss tenancy law. The list of control variables includes log wages, average years of education, a household formation dummy (family $=1$, single household $=0$ ), average household age, number of children, a dummy for recent marriage, and a dummy for recent children. Panel B shows the effects of a one standard deviation increase in rents and house prices, which correspond to an increase of CHF 2,249 and CHF 172,306, respectively. Since the panel fixed effects regression applies OLS to the individual demeaned variables, these standard deviations are also from demeaned variables. Panel $\mathrm{C}$ shows the indirect effect on the propensity to move, if the shock occurs not at the house price level directly, but at the level of immigration. In particular, the coefficients show the effect of a one standard deviation increase in immigration from Western Europe and OECD countries ( 0.59 pct. points, variable is two-way demeaned, see Table 4$)$ on the propensity to relocate using house prices as the transmission channel. 
Table 8 The Wage Channel of Displacement

Panel A: One Percent Increase in Wages

\begin{tabular}{lcccc}
\hline & \multicolumn{2}{c}{ Tenants } & \multicolumn{2}{c}{ Owners } \\
\cline { 2 - 5 } Log(Wage) & $\mathbf{0 . 0 1 6}^{*}$ & $\mathbf{0 . 0 1 1 ^ { * }}$ & -0.002 & -0.003 \\
Interaction: HH. Intends to move & - & $\mathbf{0 . 0 4 2 ^ { * }}$ & - & $\mathbf{0 . 0 1 6}^{*}$ \\
\cline { 2 - 5 } Household Fixed Effects & YES & YES & YES & YES \\
Time-Varying Household Controls & YES & YES & YES & YES \\
Observations & 24,237 & 20,347 & 23,419 & 23,419 \\
Adj.R-Squared & 0.33 & 0.40 & 0.21 & 0.34 \\
\hline
\end{tabular}

Panel B: One Standard Deviation Increase in Wages (CHF 56,861)

Tenants

Owners

Log(Wage $)$

Interaction: HH. Intends to move

\begin{tabular}{cccc}
\multicolumn{2}{c}{ Tenants } & \multicolumn{2}{c}{ Owners } \\
\hline 0.60 & 0.35 & - & - \\
- & 1.68 & - & 0.95
\end{tabular}

Panel C: Indirect Effect of One Standard Deviation Increase in Immigration (0.59 pct. points)

\begin{tabular}{lcccc}
\hline & \multicolumn{3}{c}{ Tenants } & \multicolumn{3}{c}{ Owners } \\
\cline { 2 - 4 } $\log ($ Rents) or $\log ($ Prices) & 0.007 & 0.005 & - & - \\
Interaction: HH. Intends to move & - & 0.020 & - & 0.007
\end{tabular}

This table shows the effect of an increase in wages on the propensity that a household relocates to a new municipality.

The estimating equation is $\mathrm{Move}_{i t+1}^{\text {tenant/owner }}=\beta_{1} \mathrm{~W}_{i t}+\beta_{2} D_{i t}+\beta_{3} W_{i t} \cdot D_{i t}+\beta_{4}^{\prime} \cdot$ controls $s_{t}+\varepsilon_{i t}^{r}$. Panel A shows the regression coefficients on a one percent increase. We run individual regressions for tenants and owners to control for the possibility that both groups would respond differently to income shocks. The list of control variables includes log rents in tenant regressions and log single family house prices in owner regressions, average years of education, a household formation dummy (family $=1$, single household $=0$ ), average household age, number of children, a dummy for recent marriage, and a dummy for recent children. Panel B shows the effects of a one standard deviation increase in wages, which correspond to an increase of CHF 56,861. Since the panel fixed effects regression applies OLS to the individual demeaned variables, these standard deviations are also from demeaned variables. Panel $\mathrm{C}$ shows the indirect effect on the propensity to move, if the shock occurs not at the wage level directly, but at the level of immigration. In particular, the coefficients show the effect of a one standard deviation increase in immigration from Western Europe and OECD countries ( 0.59 pct. points, variable is twoway demeaned see Table 5) on the propensity to relocate using wages as the transmission channel. 
Table 9: The Sentiment Channel of Displacement (Aggregate Level Effects)

\begin{tabular}{lcc}
\hline & OLS & SAR \\
\hline Net Immigration West and OECD & $\mathbf{- 0 . 3 7 ^ { * }}$ & $\mathbf{- 0 . 2 3}^{*}$ \\
Net Immigration RoW & -0.01 & 0.016 \\
Spatial Lag & - & $\mathbf{0 . 5 1}^{*}$ \\
\hline Municipality Fixed Effects & YES & YES \\
Time Fixed Effects & YES & Yes \\
Observations & 44,137 & 44,137 \\
Adj.R-Squared & 0.99 & 0.99
\end{tabular}

This table shows the effects of a one percentage point increase in immigration on the annual percentage change in the incumbent Swiss population within a municipality.

The estimating equation is $\ln \left(\right.$ Swiss $\left._{t}^{r}\right)=\left(I_{N} \otimes l_{T}\right) \mu+\rho\left(W_{N} \otimes I_{T}\right) \ln \left(\right.$ Swiss $\left._{t}^{r}\right)+\alpha_{1} O E C D_{3 y r}^{r}+\alpha_{2}$ RoW $_{3 y r}^{r}+\alpha_{3}^{\prime}$ controls $_{t}+\varepsilon_{t}^{r}$. Immigration is measured as exogenous net immigration as a share of the local population over the last 3 years (from $t-3$ to $t-1$ ). The regression controls for municipality and time fixed effects, house prices, and wages. The coefficients for municipality and time fixed effects are included in the estimation which results in high R-squared values. However, Im, Pesaran and Shin (2003) panel unit root tests reject the null hypothesis of a unit root in the variables. 
Table 10: The Sentiment Channel of Displacement (Household Level Effects)

Panel A: One Percent/Percentage Point Increase in immigration

\begin{tabular}{lcccc}
\hline & \multicolumn{2}{c}{ Tenant } & \multicolumn{2}{c}{ Owner } \\
\cline { 2 - 5 } Net Immigration West and OECD & $\mathbf{1 . 0 5 3}^{*}$ & $\mathbf{0 . 9 0 7}^{*}$ & $\mathbf{0 . 4 5 5}^{*}$ & $\mathbf{0 . 5 4 1}^{*}$ \\
Net Immigration RoW & 0.114 & 0.079 & $\mathbf{0 . 4 8 6}^{*}$ & $\mathbf{0 . 3 3 9}^{*}$ \\
Net Im. W.\& OECD*(HH. Intends to move) & - & $\mathbf{2 . 1 1 5}^{*}$ & - & $\mathbf{1 . 6 6 1}^{*}$ \\
Net Im. RoW*(HH. Intends to move) & - & $\mathbf{0 . 5 1 9}^{*}$ & - & $\mathbf{0 . 6 6 2}^{*}$ \\
Household Fixed Effects & YES & YES & YES & YES \\
Time-Varying Household Controls & YES & YES & YES & YES \\
Observations & 24,204 & 20,324 & 20,015 & 17,235 \\
Adj.R-Squared & 0.33 & 0.40 & 0.21 & 0.34 \\
\hline
\end{tabular}

Panel B: One Standard Deviation Increase in immigration ( 0.59 pct. points)

\begin{tabular}{lcccc}
\hline & \multicolumn{2}{c}{ Tenant } & \multicolumn{2}{c}{ Owner } \\
\cline { 2 - 5 } Net Immigration West and OECD & 0.65 & 0.56 & 0.27 & 0.31 \\
Net Immigration RoW & - & - & 0.31 & 0.26 \\
Net Im. W.\& OECD*(HH. Intends to move) & - & 1.27 & - & 0.99 \\
Net Im. RoW*(HH. Intends to move) & - & 0.38 & - & 0.49 \\
\hline
\end{tabular}

This table shows the direct effect from immigration on displacement.

The estimating equation is $\mathrm{Move}_{i t+1}^{\text {tenant/owner }}=\beta_{1} O E C D_{3 y r}^{r}+\beta_{2} \mathrm{RoW}_{3 y r}^{r}+\beta_{3}^{\prime}$ controls $_{t}+\varepsilon_{i t}^{r}$. Panel A shows the effect from a one percentage point increase in net immigration. We run individual regressions for tenants and owners to control for the possibility that both groups would respond differently to the presence of immigrants. The list of control variables includes log rents in tenant regressions and log single family house prices in owner regressions, average years of education, a household formation dummy ( family $=1$, single household $=0$ ), average household age, number of children, a dummy for recent marriage, and a dummy for recent children. Panel B shows the effects of a one standard deviation increase in immigration, which correspond to an increase of 0.59 percentage points. Since the panel fixed effects regression applies OLS to the individual demeaned variables, these standard deviations are also from demeaned variables. 


\section{Appendix A: Exogenous Push Immigration and Actual Immigration}

In this paper, we aim to measure the causal effect of immigration by transforming the raw immigration numbers into exogenous or "pushed" net immigration measured as a percentage of the native Swiss population. This method follows Card (2001) and has been routinely used in the recent labor market literature (e.g. in Basten and Koch, 2015). However, it is instructive to compare the transformed exogenous immigration numbers to actual numbers in order to see the extent of the variable transformation. Figure A1 shows actual and transformed immigration for selected regions. Immigration is measured as net immigration relative to the local Swiss population. The solid line shows the actual annual immigration numbers over the period 1992-2013 and the dashed line shows the transformed exogenous values. The two lines deviate to some extent, indicating that presence of endogeneity in the raw immigration numbers. However, the comovement between the lines is generally quite high. The sample correlation is 0.82 for Zurich, 0.89 for Geneva, and 0.72 for Lausanne. At first glance, Figure A1 suggests that endogeneity appears to be only a minor issue. However, we find that the correlation is only high for large municipalities and declines for smaller rural areas. The correlation between actual and exogenous immigration when averaged over all 2,323 municipalities is 0.2 . Overall, these results indicate that endogeneity can have distorting effects that need to be properly addressed. According to the literature, the Card (2001) method that is used in this paper is one such tool. 
Figure A1: Exogenous and Actual Net Immigration

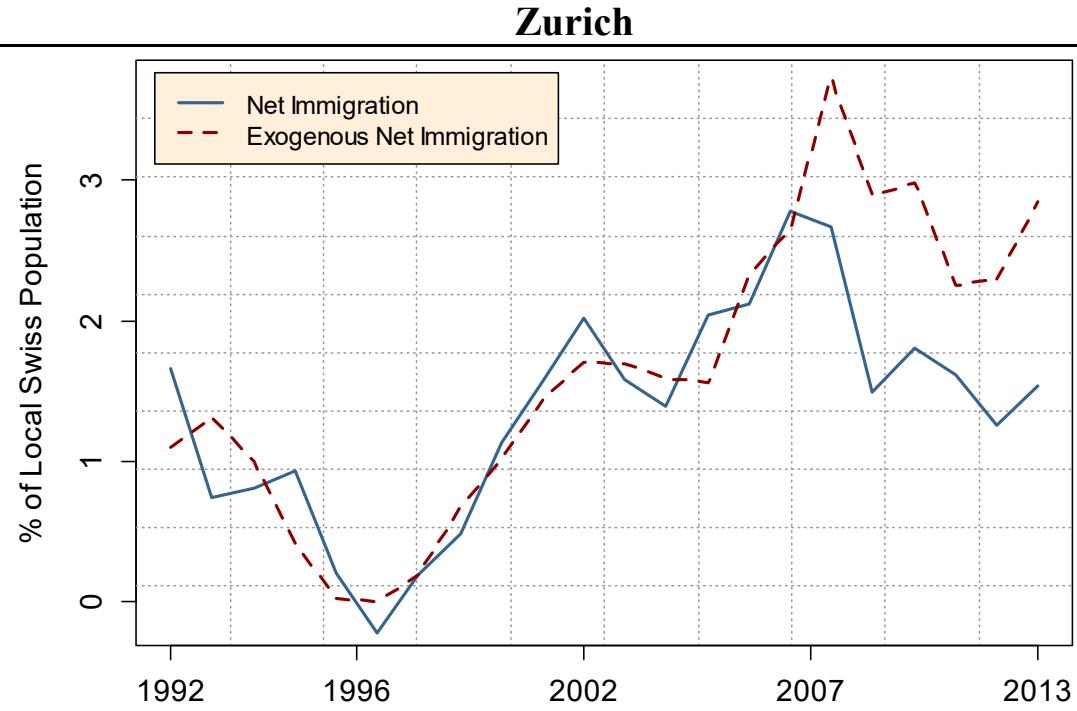

Geneva

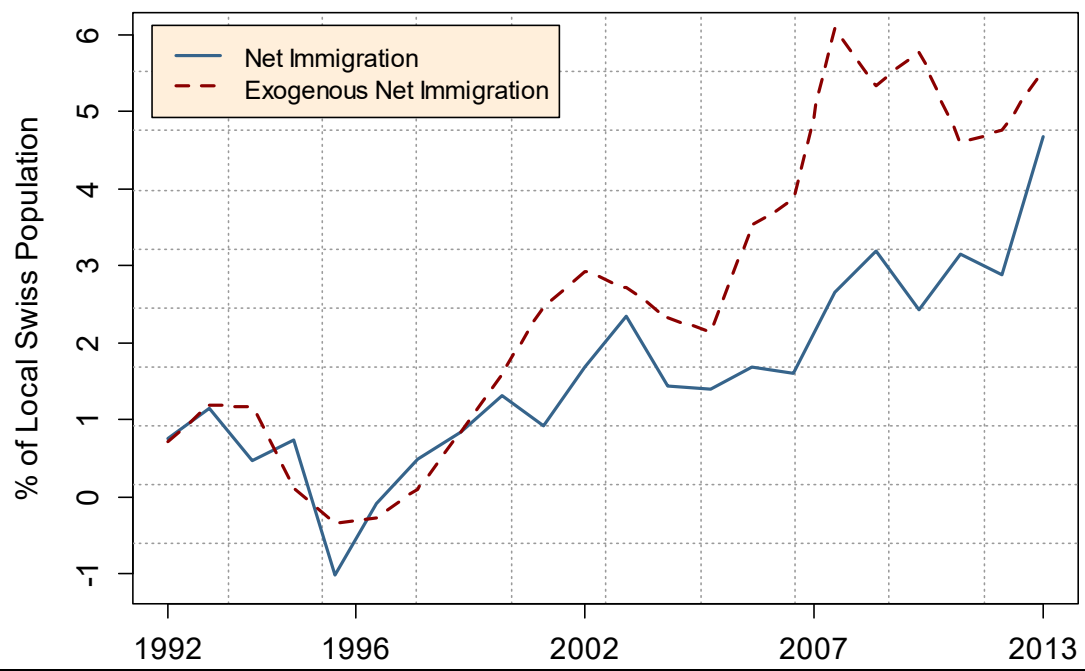

Lausanne

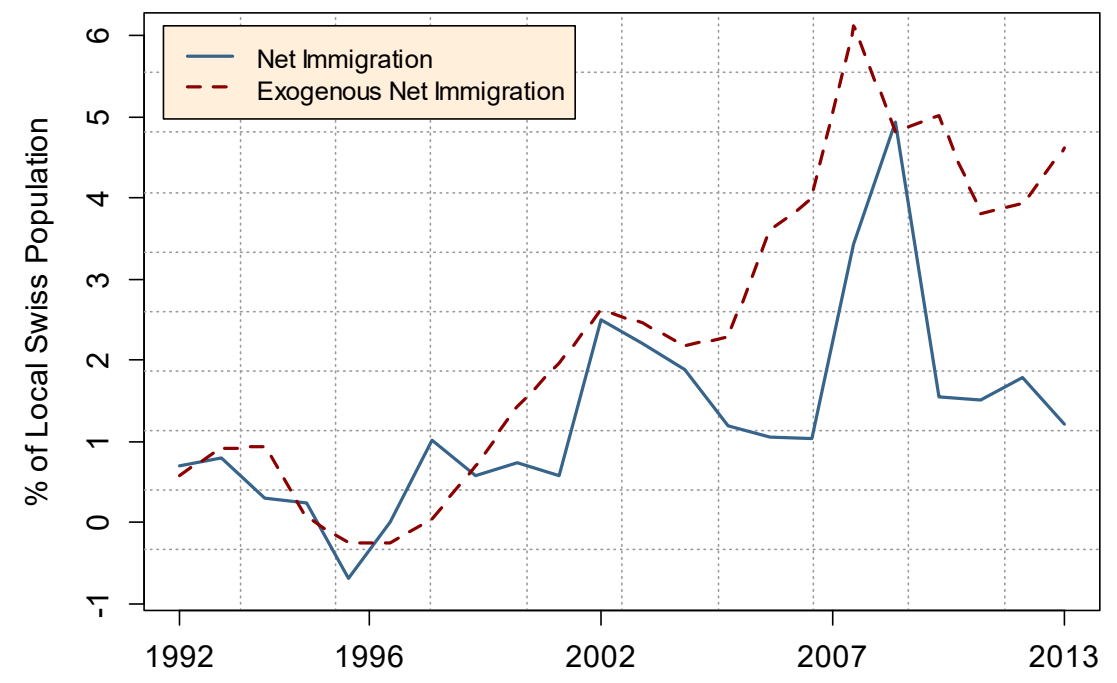




\section{Appendix B: The Panel Spatial Autoregressive Model and Individual Country Results}

In this paper, we examine the relationship between house prices and immigration on the municipality (Swiss "Gemeinde") level. As the typical municipality size is rather small (the median number is 1,100 inhabitants per municipality) we expect a strong spatial interaction between house prices in neighboring municipalities. The standard specification for a spatial interaction process in which house prices in one region are jointly determined by the house prices in neighboring regions is the spatial panel fixed effects lag model (Anselin et al., 2006; Elhorst, 2010) ) $^{38}$.

$$
\begin{aligned}
& H P=\left(I_{N} \otimes l_{T}\right) \mu+\rho\left(W_{N} \otimes I_{T}\right) H P+X \beta+\varepsilon \\
& \varepsilon_{i t} \sim I I D\left(0, \sigma_{\varepsilon}^{2}\right)
\end{aligned}
$$

House prices, $H P$, depend on a set of individual specific effects $\mu$, a spatial lag $\left(W_{N} \otimes I_{T}\right) H P$, and the regressor matrix $X$. The individual specific effects $\mu$ capture characteristics that vary across municipality but do not change over time. For instance, house prices in heavily urbanized areas such as Zurich city are higher on average than in more rural areas. House prices along the lake of Zurich are also known to have higher levels of house prices and those level shifts are captured in $\mu$. The individual specific effects are removed by pre-multiplying the variables with the fixed-effects transformation matrix $Q=I_{N T}-\frac{1}{T} I_{N} \otimes l_{T} l_{T}^{\prime} \cdot 39$ The spatial lag $\left(W_{N} \otimes I_{T}\right) H P$ models the spatial dependence among house prices. With neighboring municipalities well within driving distance, we expect an increase in house prices to spill over to neighboring municipalities. The spatial lag coefficient $\rho$ measures the strength of spatial interactions and, for most practical applications, is in the range between 0 and $1 .{ }^{40}$ Ignoring the spatial interaction among regions carries the implicit assumption that a positive demand shock in one municipality increases house prices equally within that region but has no effect when crossing the border into another municipality. This strict assumption is unlikely to hold in practice. If ignored in the model, the spatial link

${ }^{38}$ An alternative model specification would be the spatial panel error model that does not incorporate the spatial interaction directly but controls for its effects in the error term. In our paper, we are interested in directly measuring the spatial dissemination of housing market, labor market, and immigration shocks so that the fixed effects lag model is a better choice.

${ }^{39}$ In this paper, we stack our data in the classical panel form (Hsiao, 2003) with time as the fast index and municipalities as the slow index. We thereby do not follow the majority of the spatial panel literature who use individuals as the fast index and time as the slow index. Our specification therefore differs slightly from standard textbook forms. For instance the standard specification for the $Q$ matrix in the spatial econometrics literature would be $Q=I_{N T}-\frac{1}{T} l_{T} l_{T}^{\prime} \otimes I_{N}$.

40 Technically speaking, stationarity requires that $1 / \omega_{\min }<\delta<1 / \omega_{\max }$ where $\omega_{\min }$ and $\omega_{\max }$ denote the smallest and the largest eigenvalue of the weight matrix W. In our case, this would be $-2.18<\delta<1$. 
between regions appears in the error term and leads to biased coefficient estimates (LeSage and Pace, 2009). Explicitly modeling the spatial interaction among regions not only avoids this bias but also allows to estimate house price spillovers across regions.

Finally, the regressor matrix $X$ includes our measure of net immigration and a number of control variables. In our specification in Eq.(B1), the regressors have no direct spatial interaction but can cause indirect spillovers via house price changes. For instance, immigration to region $i$ does not increase house prices in neighboring region $j$ directly (immigration is confined to region $i$ ), but increases house prices in region $i$ which in turn lead to higher house prices in region $j$. Therefore, the only variable in our model that is allowed to propagate spatially is house prices. All other variables function indirectly through the house price link.

An important issue in the application of spatial regression models is the correct interpretation of the marginal effects. In standard OLS, the marginal effect of variable $x_{r}$ in region $i$ is defined as:

$$
\frac{\partial H P_{i}}{\partial x_{i, r}}=\beta_{r} \quad ; \quad \frac{\partial H P_{i}}{\partial x_{j, r}}=0 \forall j \neq i
$$

Since there is no spatial interaction in OLS, shocks that occur outside of region $i$ have no effect on that region. The situation is more elaborate for spatial autoregressive models:

$$
\begin{gathered}
Y\left(I_{N T}-\rho\left(W_{N} \otimes I_{T}\right)\right)=X \beta+\varepsilon \\
Y=\left(I_{N T}-\rho\left(W_{N} \otimes I_{T}\right)\right)^{-1} X \beta+\left(I_{N T}-\rho\left(W_{N} \otimes I_{T}\right)\right)^{-1} \varepsilon \\
\frac{\partial H P_{i}}{\partial x_{i, r}}=S_{r}(W)_{i i}=\left(I_{N T}-\rho\left(W_{N} \otimes I_{T}\right)\right)^{-1} \beta_{r} ; \frac{\partial H P_{i}}{\partial x_{j, r}}=S_{r}(W)_{i j}
\end{gathered}
$$

The marginal effect in spatial autoregressive models is therefore not a scalar $\beta_{r}$ but a large NTxNT coefficient matrix showing the interaction between a change in house prices in one region at one point in time and all other regions during all points in time. Since our model is a purely static model, there is only contemporaneous spatial interaction and we can reduce the $S_{r}(W)$ matrix to a smaller $N x N$ coefficient matrix. This reduced $S_{r}(W)$ matrix shows the direct impacts on the main diagonal, i.e. the response of the region in which the shock originates. The off-diagonal elements denote the indirect impacts or spillover effects. The column sum of the $S_{r}(W)$ matrix shows the total impacts, the effect of a shock in one municipality on itself and all other municipalities. To facilitate the interpretation of the coefficients, LeSage and Pace (2009) propose an estimate of the average direct effect as the average of the main diagonal of $S_{r}(W)$ :

$$
\bar{M}(r)_{\text {direct }}=n^{-1} \operatorname{tr}\left(S_{r}(W)\right)
$$


The average direct effect is similar to the coefficient vector $\beta$ from Eq.(B1) but contains the feedback effects that are returned from neighboring regions. The coefficient vector $\beta$ can be interpreted as the immediate or first round effect while $\bar{M}(r)_{\text {direct }}$ measures the long-run effect that includes $\beta$ but also the feedback effects that accumulate over time. Note that the term "long-run" is not well defined in our context since our model is purely static and hence, the dynamic path to the long run is unknown. The average total effect that includes the direct effect but also the indirect effect that result from spillovers can be estimated as the average of all entries of the $S_{r}(W)$ matrix:

$$
\bar{M}(r)_{\text {total }}=n^{-1} \iota_{n}^{\prime} S_{r}(W) \iota_{n}
$$

A vector of ones, $l_{n}$, first generates the column sums $\imath_{n}^{\prime} S_{r}(W)$ and then generates the total sum as the sum of the column sums $\imath_{n}^{\prime} S_{r}(W) l_{n}$. The total impacts from Eq.(B7) are used in the graphical summary of immigration effects in Figure 6 of the paper. Finally, the indirect effects can be obtained as the difference of the total effect and the direct effect:

$$
\bar{M}(r)_{\text {indirect }}=\bar{M}(r)_{\text {total }}-\bar{M}(r)_{\text {direct }}
$$

Spatial models therefore require more effort in their interpretation but in return offer a much richer interaction than simple non-spatial OLS regressions.

Table 4 in the paper showed that house price effects from immigration differ between Western Europe and OECD countries on the one hand and rest of world countries on the other. The classification of countries into these two groups had the advantage that sufficient observations for each municipality and year are available. For completeness, we show the house price effects of individual countries in Table B1 below. The first specification shows the effect from all countries. The second specification uses the groups from the paper and repeats the results from Table 4. The third specification shows individual country effects. Germany provides the largest group of immigrants but house price effect is small compared to other countries such as France, Spain, and the UK. Other countries such as former Yugoslavian countries, Italy and Turkey have negative coefficient estimates, suggesting that an increase in immigration from these countries can lead to lower house prices in the target municipalities and neighboring regions. The last specification distinguishes between residency permits and shows that the effects of medium-term residents having permit B do not differ from those with a long-term residency permit $\mathrm{C}$. Immigrants with refugee status are estimated to have slightly negative house price effects. 
Table B1:The Effects of Immigration on House Prices

\begin{tabular}{|c|c|c|c|c|c|c|c|c|c|c|c|c|c|c|c|c|}
\hline & SR & $\mathbf{L R}$ & $10 N$ & $20 \mathrm{~N}$ & SR & $\mathbf{L R}$ & $10 N$ & $20 \mathrm{~N}$ & SR & $\mathbf{L R}$ & $10 \mathrm{~N}$ & $2 \mathrm{ON}$ & SR & LR & $10 N$ & $20 N$ \\
\hline Spatial Lag $\rho$ & $0.83^{*}$ & - & - & - & $0.82^{*}$ & - & - & - & $0.82^{*}$ & - & - & - & $0.83^{*}$ & - & - & - \\
\hline All Countries & $0.49^{*}$ & 0.61 & 0.17 & 0.08 & - & - & - & - & - & - & - & - & - & - & - & - \\
\hline West. Eu. \& OECD & - & - & - & - & $1.15^{*}$ & 1.43 & 0.39 & 0.18 & - & - & - & - & - & - & - & - \\
\hline Germany & - & - & - & - & - & - & - & - & $0.16^{*}$ & 0.20 & 0.05 & 0.03 & - & - & - & - \\
\hline Former Yugoslavia & - & - & - & - & - & - & - & - & $-1.37^{*}$ & -1.70 & -0.47 & -0.22 & - & - & - & - \\
\hline France & - & - & - & - & - & - & - & - & $2.22^{*}$ & 2.76 & 0.75 & 0.35 & - & - & - & - \\
\hline Spain & - & - & - & - & - & - & - & - & $1.22^{*}$ & 1.52 & 0.41 & 0.19 & - & - & - & - \\
\hline Portugal & - & - & - & - & - & - & - & - & $1.73^{*}$ & 2.15 & 0.59 & 0.27 & - & - & - & - \\
\hline U.S. & - & - & - & - & - & - & - & - & $0.46^{*}$ & 0.57 & 0.16 & 0.07 & - & - & - & - \\
\hline U.K. & - & - & - & - & - & - & - & - & $2.01^{*}$ & 2.50 & 0.68 & 0.32 & - & - & - & - \\
\hline Italy & - & - & - & - & - & - & - & - & $-0.29^{*}$ & -0.36 & -0.10 & -0.05 & - & - & - & - \\
\hline Austria & - & - & - & - & - & - & - & - & $0.16^{*}$ & 0.20 & 0.05 & 0.03 & - & - & - & - \\
\hline Turkey & - & - & - & - & - & - & - & - & -0.43 & -0.53 & -0.15 & -0.07 & - & - & - & - \\
\hline Rest of World & - & - & - & - & $0.37^{*}$ & 0.46 & 0.13 & 0.06 & $1.89^{*}$ & 2.35 & 0.64 & 0.30 & - & - & - & - \\
\hline Vacancy Rate & $-0.05^{*}$ & -0.06 & -0.02 & -0.01 & $-0.06^{*}$ & -0.07 & -0.02 & -0.01 & $-0.05^{*}$ & -0.06 & -0.02 & -0.01 & $-0.04^{*}$ & -0.05 & -0.01 & -0.01 \\
\hline Residency Permit B & - & - & - & - & - & - & - & - & - & - & - & - & $1.35^{*}$ & 1.68 & 0.46 & 0.21 \\
\hline Residency Permit C & - & - & - & - & - & - & - & - & - & - & - & - & $1.56^{*}$ & 1.94 & 0.53 & 0.25 \\
\hline Refugees & - & - & - & - & - & - & - & - & - & - & - & - & -0.02 & -0.02 & -0.01 & 0.00 \\
\hline
\end{tabular}

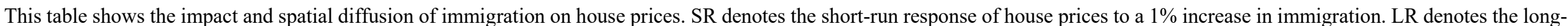

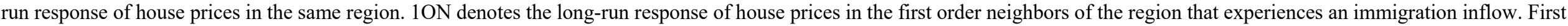

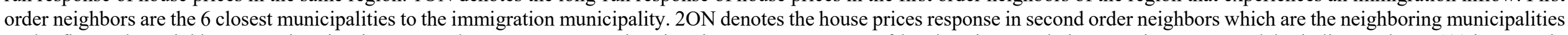

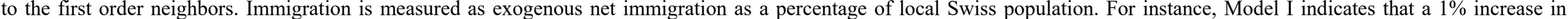

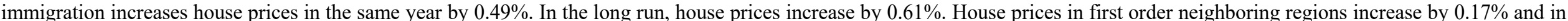
second order neighboring regions by $0.08 \%$. 